\title{
Do the Higher Educated Unemployed Crowd out the Lower Educated Ones in a Competition for Jobs?*
}

\author{
Bart Cockx ${ }^{\dagger}$ and Muriel Dejemeppe ${ }^{\ddagger}$ \\ Institut de Recherches Economiques et Sociales, \\ Université catholique de Louvain
}

June 28, 2002

\begin{abstract}
This paper proposes a new method to estimate the extent of job competition between workers with different schooling levels. We estimate the structural parameters of a matching function generalised to incorporate crowding out effects. We use flow data out of unemployment containing information on the level of educational attainment of the worker, but not on the level of schooling required by the employer for the job. The method therefore avoids the bias induced by mismeasurement in the educational requirements. Applied to Belgian data, we find evidence of significant crowding out among dismissed workers, particularly at the highest schooling levels.
\end{abstract}

JEL classification: J63, J64, C41

Keywords: Job competition, crowding out, overeducation, matching function, duration analysis.

${ }^{*}$ This paper has benefited from the comments of Marc Gurgand, Mareva Sabatier, Henri Sneessens, Gerard van den Berg, Bruno Van der Linden and Etienne Wasmer. We also thank participants to the workshop on 'Mismatch, job competition and over-education' (7-8 June 2002, IRES, Louvain-la-Neuve, Belgium) for their comments. Financial support from the 'Fonds National de la Recherche Scientifique' is gratefully acknowledged. This research is also part of a programme supported by the Belgian government (Poles d'Attraction inter-universitaires PAI P4/01) and a programme supported by the Service d'Etudes et de la Statistique of the Walloon region. We thank the Office National de l'Emploi and the Office communautaire et Régional de la Formation Professionnelle et de l'Emploi for providing the data.

${ }^{\dagger}$ Département des Sciences Economiques and Institut de Recherches Economiques et Sociales, Université catholique de Louvain, and IZA, Bonn. Address: Place Montesquieu, 3, 1348 Louvain-la-Neuve, Belgium. Tel : 32.10.47.34.39, Fax : 32.10.47.39.45, E-mail : cockx@ires.ucl.ac.be.

${ }^{\ddagger}$ Fonds National de la Recherche Scientifique and Institut de Recherches Economiques et Sociales, Université catholique de Louvain. Address: Place Montesquieu, 3, 1348 Louvain-la-Neuve, Belgium. Tel : 32.10.47.41.00, Fax : 32.10.47.39.45, E-mail : dejemeppe@ires.ucl.ac.be. 


\section{Introduction}

Low educated workers became increasingly vulnerable to unemployment during the last decades in Belgium. Figure 1 depicts the unemployment rate by schooling level of this country in 1977, 1981 and $1998^{1}$. In 1998, the unemployment rate for less educated workers (with at most a lower secondary degree ${ }^{2}$ ) increased by a factor of 2.5 as compared to its level in 1977 while this factor only amounts to 1.25 for workers who completed higher education. In 1995, the Belgian ratio between the unemployment rate of these two schooling groups was one of the largest among 15 OECD countries (see OECD 1997a). However, the relative rise of low skilled unemployment is a particular feature of Wallonia, the French speaking region in the South ${ }^{3}$, as illustrated in Figure 2.

\section{INSERT FIGURES 1 AND 2 APPROXIMATELY HERE}

Among the possible causes of these evolutions, the story of a skill biased technological change has been rather popular (see, e.g., Drèze and Sneessens 1997; Autor et al. 1998; Berman et al. 1998; Machin and Van Reenen 1998). More recently, some authors argued that the technological progress cannot be the only cause of the diverging unemployment rates between skilled and unskilled workers: Higher educated workers may crowd out lower educated ones in their competition for jobs (see Gautier 2002; Pierrard and Sneessens 2002; Albrecht and Vroman 2001; Dolado et al. 2000; Borghans and de Grip 2000; Green et al. 1999). Crowding out can be induced by a general reduction in the demand for labour or by a growth in supply of highly educated workers outpacing the growth in demand of high skills. In both cases, real wage rigidity results in job scarcity on the high skill segment, thereby inducing more educated workers to extend job search on the skill segment below their own.

Most of the existing evidence on job competition relies on measures of overeducation. These measures report the share of workers with a higher schooling level than the one required to perform the job. There is a growing interest in the overeducation literature, witness the special issue of the Economics of Education Review (19, April 2000) on

\footnotetext{
${ }^{1}$ In Belgium, there is no time-series on the working population by level of educational attainment. This information is available on an annual basis in the labour force surveys since 1989 only. In Figure 1, unemployment rates by schooling level are calculated on the basis of a socio-economic survey in 1977 and the population census in 1981.

${ }^{2}$ A lower (resp. upper) secondary degree corresponds to 9 (resp. 12) years of education.

${ }^{3}$ Belgium is divided into three regions: Wallonia, Flanders and Brussels.
} 
this topic. The incidence of overeducation ranges between $10 \%$ and $35 \%$ in European countries (see Green et al. 1999 and Hartog 2000). There is also some evidence of increasing overeducation over the seventies and early eighties in the United Kingdom, the Netherlands, Portugal and Spain. A limited number of studies tried to evaluate the incidence of overeducation for Belgium (see Van Hoof 1996 and Denolf et al. 2001). Based on a vacancy survey to employers, Denolf et al. (2001) conclude that $24 \%$ of the newly hired workers were overeducated in 2000 and that this proportion is somewhat higher in Wallonia (31\%).

There is an important measurement problem in the literature on overeducation (see Green et al. 1999). The results are sensitive to the classification of jobs according to the required schooling level. Often workers self-report this information. But even if the required schooling level is obtained from employers or external experts, one is not exempted from biases. For instance, employers can raise their educational requirements in order to attract the best candidates for the job or simply because they expect a large number of highly educated candidates. If the schooling profile of the job is evaluated through external experts, the information must be frequently updated since the job content may change with the introduction of new technologies.

Only a few studies analyse the extent of job competition on the basis of econometric techniques. Recently, Gautier et al. (2002) test whether more highly educated workers occupy simple jobs in cyclical downturns on the basis of a firm-worker data set. To that purpose, they measure, for each job complexity level, the difference between average schooling of the inflow and the outflow (at the firm level), and test whether this variable is larger in downturns ${ }^{4}$. They found evidence of countercyclical job competition at only one of the lower job complexity levels.

Van Ours and Ridder (1995) and Gurgand (1999) use a more indirect estimation approach. Job competition implies that the number of hirings at a particular level of education depends also on the number of job seekers at other levels. If the labour market was perfectly segmented this would not be the case. These studies exploit this distinguishing feature to identify job competition. Based on data on filled vacancies by schooling requirement, Van Ours and Ridder estimate a matching function allowing for job competition between unemployed workers with different educational attainments.

\footnotetext{
${ }^{4}$ To the extent that the definition of job complexity is stable over the cycle, this method avoids the above-mentioned measurement critique. However, it only allows to evaluate the evolution of job competition and not its extent at a particular moment of time.
} 
They do not find evidence for job competition, except at the top segment of the labour market. Gurgand tests empirically whether the number of more educated unemployed workers reduces the hiring probability of the less educated workers. His findings confirm significant job competition between workers with higher education and those with secondary education.

In this paper, we estimate, for the period June 1989 - February 1994, the extent of job competition among unemployed dismissed workers in Wallonia based on a similar estimation approach. As in Van Ours and Ridder (1995), we generalise the specification of the matching function to account for crowding out effects. Van Ours and Ridder allow workers of each skill segment to compete for jobs in all other segments. We impose more structure by assuming that unemployed workers, apart from searching in their own segment, can only seek in the segment just below their own. We also deviate from their estimation approach. We estimate the structural parameters of the generalised matching function by using flow data from unemployment containing information on the level of educational attainment of the worker, but not on the level of schooling required by the employer for the job. Therefore, our method avoids the bias induced by mismeasurement in the educational requirements. In addition, as to avoid an equivalent measurement issue, we control for different demand conditions across skill segments by estimating the distribution of vacancies by schooling level.

Gurgand (1999) accounts for this measurement bias in a similar approach as ours. However, he does not allow for different demand conditions across skill segments. Moreover, he estimates a reduced form model from which the structural crowding out parameters of the generalised matching function cannot be deduced.

The plan of the paper is as follows. In the next section, we derive the theoretical expression of the job finding rate in the presence of job competition. Section 3 describes the data. In Section 4, we derive the regression model. Section 5 discusses the estimation results. The concluding section summarises our findings and provides policy recommendations.

\section{Model specification}

\subsection{Definitions, notations and assumptions}

We consider a segmented labour market in which labour demand is differentiated according to the level of education required on the job and labour supply according to 
the level of educational attainment of the individuals. The level of education is indexed by $i \in(1,2, \ldots, I)$, the type of segment and the type of individual being characterised by a subscript and a superscript respectively. $I$ is the highest schooling level. Labour demand is captured by the number of vacancies firms post. Labour supply is restricted to unemployed workers effectively looking for a job.

We describe the meeting process between the job offers and the unemployed workers by a matching function and we treat matching as a continuous-time process (as in Coles and Petrongolo 2002). In our framework, the matching function relates, at calendar time $\tau$, the intensity of hirings in segment $i, F_{i \tau}$, to the number of vacancies and the number of effective job seekers in segment $i$, respectively $V_{i \tau}$ and $S_{i \tau}$. The latter number is measured in efficiency units to account for heterogeneity within each segment. In the empirical analysis, observed personal characteristics, such as unemployment duration, are used to approximate the heterogeneity within segments. Assuming a Cobb-Douglas specification without any restriction on its returns to scale, the matching function in segment $i$ is given by:

$$
F_{i \tau}=\left(S_{i \tau}\right)^{\alpha}\left(V_{i \tau}\right)^{\beta}
$$

where $\alpha>0$ and $\beta>0$ are assumed to be independent of $i$.

If the labour market is perfectly segmented, (i) the unemployed workers of education level $i, U_{\tau}^{i}$, look for jobs only in their own segment: $S_{i \tau}=\bar{e}_{\tau}^{i} U_{\tau}^{i}$ where $\bar{e}_{\tau}^{i}$ represents the average matching efficiency of the unemployed workers with schooling level $i$ (see Jackman et al. 1989), and (ii) the vacancies requiring the education level $i, V_{i \tau}$, can only be filled by workers having the corresponding level: $F_{i \tau}=F_{\tau}^{i}$, where $F_{\tau}^{i}$ is the number of vacancies filled by unemployed workers with level of education $i$. We allow the average matching efficiency, $\bar{e}_{\tau}^{i}$, to vary between levels of education as to account for a different composition of efficiency units between these groups.

Let $\theta_{i \tau}$ denote tightness (i.e. the vacancy-unemployment ratio) in segment $i$ and $\tilde{\theta}_{i \tau}$ its equivalent measure in efficiency units:

$$
\tilde{\theta}_{i \tau}=\frac{V_{i \tau}}{\tilde{U}_{\tau}^{i}}
$$

where $\tilde{U}_{\tau}^{i}=\bar{e}_{\tau}^{i} U_{\tau}^{i}$.

Using (1) and (2), the rate at which a job seeker of education level $i$ finds a job in a perfectly segmented labour market is then given by: 


$$
h_{\tau}^{i} \equiv \frac{F_{\tau}^{i}}{U_{\tau}^{i}}=\bar{e}_{\tau}^{i}\left(\tilde{U}_{\tau}^{i}\right)^{\alpha-1}\left(V_{i \tau}\right)^{\beta}=\bar{e}_{\tau}^{i}\left(\tilde{U}_{\tau}^{i}\right)^{\alpha+\beta-1}\left(\tilde{\theta}_{i \tau}\right)^{\beta}
$$

Under the assumption of constant returns to scale (CRS), i.e. $\alpha+\beta=1$, there is a one-to-one relationship between the hiring rate of a job seeker with schooling level $i$ and tightness in his segment. If $\bar{e}_{\tau}^{i}$ is the same in each segment, disparity of the job finding rates between schooling levels can only be due to imbalance (mismatch) between the labour demand and supply across educational levels.

In the next section, we allow for job competition between workers of different schooling levels and show that this competition can also explain the divergence in job finding rates by level of education.

\subsection{The effect of job competition}

With job competition, the labour market is not perfectly segmented: Unemployed workers of schooling $i, U_{\tau}^{i}$, can search for a job in a segment requiring an educational attainment below their own; Equivalently, job offers designed for education $i, V_{i \tau}$, can now also be filled by overeducated workers. We only allow job competition at one level downward and exclude upward competition. These two assumptions are realistic given that we classify education into relatively broad categories in the empirical analysis ${ }^{5}$.

We assume simultaneous job search. All unemployed workers of type $i$ search for a job in their own segment and some fraction, $\lambda_{\tau}^{i}, i \in\{2,3, \ldots, I\}$, search simultaneously in the segment just below their own ${ }^{6}$.

The number of effective job seekers in segment $i, S_{i \tau}$, is not simply the sum of the overeducated job seekers and those with the required schooling. We deviate from Van Ours and Ridder (1995) by allowing the efficiency in the matching process to differ for overeducated job seekers. So the number of unemployed workers willing to downgrade

\footnotetext{
${ }^{5}$ The assumption that unemployed workers can only seek in the segment just below their own is also compatible with the calibration results of Albrecht et al. (2002). Based on a search equilibrium model with three types of jobs and workers, they show that this assumption fits the best data from Sweden in the nineties.

${ }^{6}$ Van Ours and Ridder (1995), in contrast, assume segmented search. Workers decide to search either in their own segment or in another. We assume simultaneous search, not because we believe that it is more realistic than segmented search. Our data do not really allow to evaluate the realism of either strategy. Our choice ensures, however, that structural parameters are identified from the data without needing to impose restrictive assumptions.
} 
becomes, in efficiency units: $z_{\tau}^{i+1}\left(\lambda_{\tau}^{i+1} \tilde{U}_{\tau}^{i+1}\right)$ where $z_{\tau}^{i}, i \in\{2,3, \ldots, I\}$, is an efficiency parameter. It can be larger or smaller than the matching efficiency when searching in one's own segment (normalised to one). Recently, Gautier (2002) shows that the employers may have a preference for one type of job seekers and that the direction of this preference is ambiguous. Ceteris paribus, an employer prefers to hire an overeducated worker if the match surplus is larger than hiring a lower educated worker. However, the employer must account for the fact that the overeducated worker will quit the firm as soon as he finds a better job. This implies higher turnover costs and reduces the expected match surplus.

The efficiency parameter $z_{\tau}^{i}$ is not identified separately from the job competition parameter since both vary in the same dimensions. Only their product, $\kappa_{\tau}^{i}=z_{\tau}^{i} \lambda_{\tau}^{i}$, is identified. However, if $\kappa_{\tau}^{i}>0$ then there is job competition, i.e. $\lambda_{\tau}^{i}>0$. Besides, if $\kappa_{\tau}^{i}>1$, the overeducated job seekers are more likely to be hired than those who have just the required schooling level, i.e. $z_{\tau}^{i}>1$.

In the presence of job competition, $S_{i \tau}=\tilde{U}_{\tau}^{i}+\kappa_{\tau}^{i+1} \tilde{U}_{\tau}^{i+1}$, and thus the matching function given in (1) takes the form:

$$
F_{i \tau}=\left(\tilde{U}_{\tau}^{i}+\kappa_{\tau}^{i+1} \tilde{U}_{\tau}^{i+1}\right)^{\alpha}\left(V_{i \tau}\right)^{\beta}
$$

Van Ours and Ridder (1995) use data on filled vacancies by schooling requirement and estimate such a matching function. In contrast, we don't have data on filled vacancies, but on flows out of unemployment by level of educational attainment. Therefore, we cannot base our analysis on equation (4); The expression is more complicated and derive below. Notice, however, that the schooling requirements of filled vacancies are reported by the employer and are therefore sensitive to the measurement bias mentioned in the introduction. We avoid this problem here. In addition, the distribution of vacancies by schooling level is estimated rather than being based on reported educational requirements (see below).

With crowding out effects, the total number of hirings for unemployed workers of education level $i, F_{\tau}^{i}$, is made of two components: $F_{i \tau}^{i}$ and $F_{i-1 \tau}^{i}$ which denote the number of vacancies filled by unemployed workers of schooling $i$ in segment $i$ and $i-1$ respectively. Since the rate at which an effective unemployed worker of type $i$ finds a job is the same for all types of effective job seekers: 


$$
\frac{F_{i \tau}^{i}}{\tilde{U}_{\tau}^{i}}=\frac{F_{i \tau}}{S_{i \tau}}=\frac{F_{i \tau}^{i+1}}{\kappa_{\tau}^{i+1} \tilde{U}_{\tau}^{i+1}}
$$

the total number of hirings for unemployed workers of education level $i$ is, by combining (4) and (5):

$$
\begin{aligned}
F_{\tau}^{i} & =F_{i \tau}^{i}+F_{i-1 \tau}^{i} \\
& =\tilde{U}_{\tau}^{i}\left[\left(\tilde{U}_{\tau}^{i}+\kappa_{\tau}^{i+1} \tilde{U}_{\tau}^{i+1}\right)^{\alpha-1}\left(V_{i \tau}\right)^{\beta}+\kappa_{\tau}^{i}\left(\tilde{U}_{\tau}^{i-1}+\kappa_{\tau}^{i} \tilde{U}_{\tau}^{i}\right)^{\alpha-1}\left(V_{i-1 \tau}\right)^{\beta}\right]
\end{aligned}
$$

Using the definition of tightness given in (2), the rate at which an unemployed worker of education $i$ finds a job is then given by:

$$
h_{\tau}^{i} \equiv \frac{F_{\tau}^{i}}{U_{\tau}^{i}}=\bar{e}_{\tau}^{i}\left[\left(S_{i \tau}\right)^{\alpha+\beta-1}\left(\tilde{\theta}_{i \tau}\right)^{\beta}\left(\frac{\tilde{U}_{\tau}^{i}}{S_{i \tau}}\right)^{\beta}+\kappa_{\tau}^{i}\left(S_{i-1 \tau}\right)^{\alpha+\beta-1}\left(\tilde{\theta}_{i-1 \tau}\right)^{\beta}\left(\frac{\tilde{U}_{\tau}^{i-1}}{S_{i-1 \tau}}\right)^{\beta}\right]
$$

In this setting, crowding out can also explain some disparity between job finding rates by schooling levels. In order to illustrate the role of job competition on the hiring rate, we impose the absence of skill mismatch $\left(\forall i: \tilde{\theta}_{i \tau}=\tilde{\theta}_{\tau}\right)$, equal average matching efficiency across segments $\left(\forall i: \bar{e}_{\tau}^{i}=\bar{e}_{\tau}\right)$ and CRS $(\alpha+\beta=1)$. Under these assumptions, equation (7) can be rearranged and becomes:

$$
h_{\tau}^{i}=\bar{e}_{\tau}\left(\tilde{\theta}_{\tau}\right)^{\beta}\left[(\underbrace{\frac{U_{\tau}^{i}}{U_{\tau}^{i}+\kappa_{\tau}^{i+1} U_{\tau}^{i+1}}}_{\leq 1})^{\beta}+\kappa_{\tau}^{i}(\underbrace{\frac{U_{\tau}^{i-1}}{U_{\tau}^{i-1}+\kappa_{\tau}^{i} U_{\tau}^{i}}}_{\leq 1})^{\beta}\right]
$$

In equation (8), the disparity of the job finding rates between schooling levels can only be explained by job competition. The first and the second term between brackets represents, respectively, the negative effect of competition from the higher schooling level on the hiring rate and the positive effect of searching for downgrading jobs: In the absence of job competition, the first and second term are respectively equal to 1 and 0 .

Undoubtedly, the hiring rate of the lowest educated workers is negatively affected by job competition since they are not able to crowd out any other workers. Likewise, the hiring rate of workers who complete the highest schooling level can only be positively 
affected by job competition since they are protected from any competition. For the intermediate schooling levels, the effect of crowding out on their outflow rate depends on the competition they face from the higher education level as compared to the competition they exert on the lower level.

Notice that with increasing returns to scale (IRS), low skilled unemployed workers could actually benefit from the competition of higher skilled workers since a greater number of effective job seekers implies a higher matching rate, other things being equal. This positive relationship stems from the fact that under IRS, the number of potential contacts between job seekers and firms increases when the size of the market is larger (see e.g. Teulings and Gautier 2000).

\section{Data}

Our analysis exploits quarterly census data relative to male workers entering insured unemployment in Wallonia. All these people are full-time registered and were previously employed. So we only observe dismissed workers. Besides the quarter of inflow, these data are stratified according to a limited number of characteristics: the unemployment duration, the age group (less than 29 years old, and between 29 and 44 years old) and the educational level. Education is grouped into four classes (in brackets, theoretical years of education): no education or elementary school (0 to 6 years), lower secondary (9 years), upper secondary (12 years) and higher education (more than 15 years). The variables $i \in\{1,2,3,4\}$ and $a \in\{1,2\}$ denote the schooling and age group respectively.

In our data set, the inflow in a given quarter is equal to the number of workers entering unemployment in this quarter and who are still unemployed at the end of the quarter in which they enter. The observation period consists of 19 quarterly intervals ${ }^{7}$, the first interval starting on the $1^{\text {th }}$ of June 1989, the last one ending on the $28^{\text {th }}$ of February 1994. So there are 18 cohorts of unemployed ${ }^{8}$ (a cohort being defined by its quarter of inflow), stratified by age group and schooling level. For each cohort, the outflows from unemployment are counted on a quarterly basis, from the time of inflow up to four quarters of unemployment or up to the end of February 1994, date at which all spells are right censored. Let the variables $\tau$ and $k$ denote respectively calendar time at the moment of outflow and unemployment duration. These variables are measured in

\footnotetext{
${ }^{7}$ Four quarters are defined: (Jun,Jul,Aug); (Sep,Oct,Nov); (Dec,Jan,Feb); (Mar,Apr,May).

${ }^{8}$ There are 18 cohorts instead of 19 as there is, by definition, no exit defined for those entering the unemployment pool in the $19^{t h}$ quarter.
} 
quarters. In our data, $\tau \in\{1,2, \ldots, 18\}$ and $k \in\{1,2,3,4\}$.

Let $U_{a k \tau}^{i}$ denotes the number of individuals of schooling $i$ and age $a$ who have been unemployed for $k-1$ quarters and who may leave unemployment within the $\tau^{\text {th }}$ quarter, and $F_{a k \tau}^{i}$ the number of these individuals leaving unemployment within the $\tau^{\text {th }}$ calendar time interval. We therefore assume that filling a vacant job is the only reason of flowing out of unemployment. In that respect, we face two main data limitations.

First, we cannot identify whether unemployment spells end in employment or in inactivity. Since the size of these movements may vary over the cycle, they can lead to biased estimates of the matching elasticities (see Petrongolo and Pissarides 2001). We believe, however, that this bias is negligible since employment is the most frequent state of exit for male unemployed workers: About $77 \%$ of them become employed ${ }^{9}$, against $47 \%$ for the women (see FOREM 1995). A second data limitation is the non-observability of the job-to-job flows. Ignoring this flow may also bias the matching elasticities since the share of employed job seekers filling vacancies varies over the business cycle (see e.g. Broersma and Van Ours 1998). However, we expect this bias to be small, since job offers are assumed to be proportional to the vacancies registered at the public employment agency. These offers are primarily aimed at unemployed people, population that we consider in our analysis.

The fraction of workers with schooling $i$, age $a$ and elapsed duration $k-1$ who fill a vacancy during the time interval $\tau$ is thus assumed to be equal to the empirical exit probability, $\hat{P}_{a k \tau}^{i}$ :

$$
\hat{P}_{a k \tau}^{i}=\frac{F_{a k \tau}^{i}}{U_{a k \tau}^{i}}
$$

Table 1 gives the empirical exit probability in the first duration interval by schooling level, averaged over the observation period and age. The hiring probability rises with the schooling level, the marginal increase being the largest for the highest educated workers.

Figure 3 shows the de-seasonalised evolution of these probabilities over time. In order to focus on the time evolution, we normalise the probability to one at the first calendar time interval (autumn 1989). The deterioration of the economic conditions from the early nineties is associated with a marked decline of the hiring probabilities. The exit probability of the less educated workers (below higher education) is more heavily hit

\footnotetext{
${ }^{9}$ In our sample, this fraction must be larger. For, the reported figure includes unemployed workers older than 44 years, who often enter a kind of early-retirement scheme.
} 
Table 1: Average empirical exit probability in the first duration interval

\begin{tabular}{cc}
\hline & $\hat{P}^{i}$ \\
\hline Higher education $(i=4)$ & 0.64 \\
\hline Upper secondary $(i=3)$ & 0.39 \\
\hline Lower secondary $(i=2)$ & 0.30 \\
\hline No education or elementary school $(i=1)$ & 0.28 \\
\hline
\end{tabular}

by the recession in 1993 than the one of the highest educated workers. There is also some seasonal variation in the outflow probability (not in the figure). The summer and the winter time impede a lot the exit from unemployment, while the labour market conditions are more favourable in the autumn and in the spring.

\section{INSERT FIGURE 3 APPROXIMATELY HERE}

Our analysis exploits the total number of job vacancies registered at the public employment agency, $V_{\tau}$, including relief jobs. Except for the latter jobs, the decision to register is taken by employers. The vacancy data provide information on the stock of vacancies at the beginning of the calendar time interval $\tau, V S_{\tau}$, and on the flow of new vacancies between $\tau-1$ and $\tau, V F_{\tau}$. Following preliminary estimations on the matching function, we only retain the number of new job offers. For, only the inflow of new vacancies significantly affects the number of matches ${ }^{10}$. For that reason, we specify the number of vacancies within the $\tau^{\text {th }}$ quarter as follows:

$$
V_{\tau}=V F_{\tau}^{O}+\pi V F_{\tau}^{R}
$$

where superscripts $O$ and $R$ stand for 'ordinary' and 'relief jobs' vacancies respectively. The parameter $\pi$ allows to examine the relative importance of relief jobs in the outflow process as compared to ordinary vacancies (as in Haskel and Jackman 1988).

\footnotetext{
${ }^{10}$ This finding is compatible with the stock-flow matching model of Coles and Smith (1998). In their setting, unemployed workers have complete information about the available job offers and apply simultaneously to all the ones that they find acceptable. This assumption implies that the stock of unemployed workers only match with the flow of new job offers. Coles and Smith's assumption captures a realistic feature of some search markets, such as available at the public employment agency, where information on job offers is highly centralised and directly available.
} 


\section{INSERT FIGURE 4 APPROXIMATELY HERE}

Figure 4 shows the flow of both types of job offers during our observation period. The share of relief jobs in the total number of vacancies registered by the employment agency is relatively high (on average 30\%) in comparison with their share in total employment. Registration of relief jobs is indeed systematic while vacancies registered by the employers at the employment agency represent only a proportion of the total number of vacant jobs in the economy (40\% in 1995, see OECD 1997b). The flow of vacancies presents a declining trend which coincides with the economic downturn characterising the early nineties ${ }^{11}$. There are also some seasonal variations in the number of vacant jobs as observed in Figure 4. The summer time impedes a lot the number of job offers while these are the largest in the spring.

\section{INSERT FIGURE 5 APPROXIMATELY HERE}

The total number of unemployed workers with schooling $i$ at the start of the $\tau^{\text {th }}$ quarter, $U_{\tau}^{i}$, is computed from our data on $U_{a k \tau}^{i}$ such as defined above ${ }^{12}$. This number is depicted in Figure 5. Given that duration is censored at four quarters in our data set, these are only short-term unemployed workers ${ }^{13}$. With the deterioration of the economic conditions, unemployment rises for all levels of education, the increasing trend being much less pronounced for the highest educated workers. All series present some seasonality: peak in the spring and off-peak in the summer.

\section{Regression model}

In the theoretical model, we assumed that the job market is segmented by schooling level $i$ and that each segment is characterised by the same job matching technology.

\footnotetext{
${ }^{11}$ The decrease in the flow of relief jobs is more surprising since we would expect higher outlays for direct job creation in recessions. It is rather budgetary restrictions and a shift to increased expenditures on training schemes in the early nineties that explain the declining importance of relief jobs in Wallonia.

${ }^{12}$ Since we have an inflow data set, not all duration classes are represented at the beginning of the observation period. We estimate the number of unemployed in the missing classes by exploiting the information on the number of unemployed workers in the observed ones. The way we estimate these numbers can be found in Appendix 1. Without this correction, there would be an artificial rise in the number of unemployed people as time proceeds, affecting the estimation of the matching elasticities.

${ }^{13}$ In the analysis, it is assumed that the long-term unemployed workers (with a duration larger than one year) are not effective candidates for the job offers (their efficiency parameter is close to zero).
} 
Within each segment, workers are heterogeneous and meet vacancies with different rates of efficiency. In the empirical analysis, we assume that the matching efficiency of an individual, $e_{a k}$, only varies according to the two observed dimensions: the age class $a$, which is also a proxy for labour market experience, and the elapsed unemployment duration $k-1$. As in Van Ours and Ridder (1995), we assume that this efficiency does not depend on the schooling level. As such, we can denote the hiring rate of any worker by $h_{a k \tau}^{i}$.

To relate $h_{\tau}^{i}$ to $h_{a k \tau}^{i}$, note that the rate at which an effective unemployed worker with schooling level $i$ and observed characteristics $a$ and $k$ finds a job is the same for all types of effective job seekers:

$$
\frac{F_{a k \tau}^{i}}{e_{a k} U_{a k \tau}^{i}}=\frac{F_{a k \tau}^{i}}{\bar{e}_{\tau}^{i} U_{\tau}^{i}}
$$

Therefore,

$$
h_{a k \tau}^{i} \equiv \frac{F_{a k \tau}^{i}}{U_{a k \tau}^{i}}=\frac{e_{a k}}{\bar{e}_{\tau}^{i}} h_{\tau}^{i}
$$

where $h_{\tau}^{i}$ is given in (7).

The theoretical model was formulated in continuous time. The available data are, however, quarterly. The flow of new vacancies, $V_{\tau}$, is the sum of jobs opened between $\tau-1$ and $\tau, F_{a k \tau}^{i}$ is the sum of individuals flowing from unemployment between $\tau-1$ and $\tau$, and $U_{\tau}^{i}$ is the stock of unemployed workers present at the beginning of quarter $\tau$. If we assume that the flow variables are constant within each quarter, equation (7) defines the constant hiring rate in the $\tau^{\text {th }}$ quarter. To capture heterogeneity, nonspecified in the theoretical model, we replace $h_{\tau}^{i}$ by $h_{a k \tau}^{i}$ and $\bar{e}_{\tau}^{i}$ by $e_{a k}$ in (7) by way of (12). The advantage of maintaining the continuous time formulation in this empirical implementation is that the value of the parameters will not depend on the time unit chosen (see Flinn and Heckman 1982).

Note that the average matching efficiency, $\bar{e}_{\tau}^{i}$, implicit in $\tilde{U}_{\tau}^{i}$ is given by:

$$
\bar{e}_{\tau}^{i}=\frac{\sum_{a, k} e_{a k} U_{a k \tau}^{i}}{U_{\tau}^{i}}
$$

Its dependence on the schooling level $i$ and on $\tau$ only reflects that the composition of effective job seekers differs between segments and over calendar time. 
Since we only exploit data on the aggregate number of job offers, the distribution of vacancies by educational requirements is unknown alongside with the job competition parameters. It would be too restrictive to impose that the total number of job offers by schooling level is only a share of those notified at the public employment agency ${ }^{14}$. For, the latter represent a (varying) proportion of the total number of vacant jobs in the economy (see Section 3). For the highest levels of education, this fraction must be smaller since the probability that an employer notifies a job at the employment agency is likely to decrease with the schooling level of the worker in demand. We therefore assume that the share of job offers by schooling level, $v_{i \tau}$, is proportional to the observed number of job offers, $V_{\tau}$, without requiring that the sum of these shares is equal to one ${ }^{15}$ :

$$
\forall i: V_{i \tau}=v_{i \tau} V_{\tau}
$$

For purposes of identification (see Appendix 2), we cannot allow for interactions between calendar time and schooling level for both vacancy and job competition parameters. We choose to impose a common evolution to the job competition parameters and let the vacancy parameters evolve differently according to the education level. Note that imposing a common time dependence to the job competition parameters does not imply that the number of overeducated job seekers in each segment, $\kappa_{\tau}^{i+1} U_{\tau}^{i+1}$, follows the same time evolution. To avoid multi-collinearity, we follow Abbring et al. (2001, pp.439$440)$ and represent the cyclical dependence of $v_{i \tau}$ and $\kappa_{\tau}^{i}$ by a second degree Chebyshev polynomial, and we allow for specific seasonal effects ${ }^{16}$ :

$$
v_{i \tau}=\exp \left(v_{i 0}+\sum_{n=1}^{2} v_{i n}^{C} p_{n}(c)+\sum_{s=2}^{4}\left(v_{i s}^{S}-v_{i 0}\right) s(c)\right), \quad i=1,2,3,4
$$

and

$$
\kappa_{\tau}^{i}=\exp \left(\kappa_{0}^{i}+\sum_{n=1}^{2} \kappa_{n}^{C} p_{n}(c)+\sum_{s=2}^{4}\left(\kappa_{s}^{S}-\kappa_{0}^{i}\right) s(c)\right), \quad i=2,3,4
$$

Since we estimate and do not condition on the observed number of vacancies by schooling requirements, the reader might be worried that the number of unemployed

\footnotetext{
${ }^{14}$ In fact, we tested this restriction. It was clearly rejected (estimation results are available on request).

${ }^{15}$ If the vacancy data were stratified by educational requirement, we could test whether the estimated distribution of job offers by level of education is compatible with the information provided by the employers in official statistics. However, this information is available since October 1995 only.

${ }^{16}$ In the estimation, we take the seasonal dummies in deviation from their mean.
} 
workers by level of education is correlated with the residuals of the regression model. The employers are likely to adjust the number of vacancies at a particular skill level to the number of available workers at that skill level (see e.g. Gautier 2002). If the actual number of vacancies deviates from the estimated one, this induces the above-mentioned correlation. We claim, however, that our specification of $V_{i \tau}$ captures the structural behaviour of employers, so that random deviations are unlikely to be correlated with the number of unemployed workers of a particular educational level.

Finally, we parametrise $e_{a k}$ according to a proportional specification:

$$
e_{a k}=\exp \left[\sum_{j=2}^{4} \gamma_{k} \delta_{j k}+\eta_{2} \delta_{2 a}\right]
$$

where $\delta_{j k}$ is the Kronecker delta, $\gamma_{k}$ is the duration effect and $\eta_{2}$ is the age effect (i.e. being aged 29-44). We normalise $e_{11}=1$.

We now turn to a description of the estimation procedure. Since we rely on grouped data, Minimum Chi-Squares is a natural estimation method (Berkson 1944, Amemiya 1981; for an application on transition data, see Cockx 1997 and Cockx and Ridder 2001). In a nutshell, this method consists in regressing a transformation of the empirical exit probability, $\hat{P}_{a k \tau}^{i}$, to its theoretical counterpart. The theoretical probability at the $k^{t h}$ duration interval for a worker of schooling $i$ and age group $a$ who is at risk of leaving unemployment within the $\tau^{\text {th }}$ quarter is:

$$
P_{a k \tau}^{i} \equiv \operatorname{Pr}(k-1 \leq T<k \mid T \geq k-1, \tau, i, a)
$$

We then link this probability to the outflow rate:

$$
P_{a k \tau}^{i}=\frac{S(k-1)-S(k)}{S(k-1)}=1-\exp \left[-h_{a k \tau}^{i}\right]
$$

where $S(k)$ is the survivor function at unemployment duration $k$.

Inverting the relationship (19) yields:

$$
z_{a k \tau}^{i}=\log \left[-\log \left(1-P_{a k \tau}^{i}\right)\right]=\log \left(h_{a k \tau}^{i}\right)
$$

If we replace the probability of leaving unemployment by its estimate, $\hat{P}_{a k \tau}^{i}$, in (20), the equality of this equation does no longer hold exactly. For, the empirical outflow 
probability is calculated on the basis of a finite sample. We follow Cockx (1997) and expand $\log \left[-\log \left(1-\hat{P}_{a k \tau}^{i}\right)\right]$ in a Taylor series around $P_{a k \tau}^{i}$. We then obtain a nonlinear heteroskedastic regression model:

$$
\hat{z}_{a k \tau}^{i}=\log \left(h_{a k \tau}^{i}\right)+\omega_{a k \tau}^{i}+\varepsilon_{a k \tau}^{i}, \quad i=1,2,3,4
$$

where $\omega_{a k \tau}^{i}$ is the approximation error reflecting the stochastic nature of the empirical exit probability $\hat{P}_{a k \tau}^{i}$ and $\varepsilon_{a k \tau}^{i}$ is a specification error which allows for random deviation from the true specification of the outflow rate (see Amemiya and Nold 1975, Cockx and Ridder 2001). We estimate the statistical model (21) by Generalized Non-Linear Least Squares. The details of the estimation procedure can be found in Appendix 3.

Because we have grouped data, we can use a $\chi^{2}$-goodness-of-fit test to evaluate the model specification (see Amemiya 1981). The weighted sum of squared residuals $(W S S R)$ is distributed $\chi_{N-N_{\theta}}^{2}$ if the model is correctly specified, where $N$ denotes the number of cells and $N_{\theta}$ is the number of parameters. Moreover, we can test the acceptability of restrictions on the parameters, for instance the absence of job competition (i.e. $\forall i, \tau: \kappa_{\tau}^{i}=0$ ). The difference between the weighted sum of squared residuals of the constrained and the unconstrained model $\left(W R S S_{0}-W R S S\right)$ is distributed $\chi_{\left(N_{\theta}-N_{\theta_{0}}\right)}^{2}{ }^{17}$.

\section{Empirical results}

The estimation results are reported in Tables 4 to 6 . In the first column of Table 4 , we report the estimation results of the regression model (21). Notice that the values of the vacancy parameters are meaningless since they contain a common scale parameter. They can only be interpreted in relative terms. Since a number of parameters are estimated with much imprecision, we first test whether we can impose some theoretical restrictions, before interpreting the results.

\section{INSERT TABLE 4 APPROXIMATELY HERE}

We first impose that $v_{1 \tau}, v_{2 \tau}$ and $v_{3 \tau}$ are constant over the business cycle, i.e. $\forall i \in$ $\{1,2,3\}: v_{i n}^{C}=0$ in (15). The estimation results are presented in the second column of Table 4. This restriction implies that the evolution of the job offers at the lower segments

\footnotetext{
${ }^{17}$ For the purpose of this test statistic, the constrained model is estimated with the estimated variance and covariance of the specification errors in the unconstrained model.
} 
follows the time pattern of $V_{\tau}$, while there is a specific time variation for the high skilled vacancies. Such a specification is not rejected at a significance level of $61 \%$.

We then look at the elasticities of the matching function (see the second column of Table 4). The estimated elasticity of matches (standard error) with respect to unemployment, $\alpha$, and vacancies, $\beta$, is respectively $0.52(0.14)$ and $0.81(0.12)$. So there is evidence of mild increasing returns to scale of the order of $1.33(0.24)$, although the sum of the elasticities does not statistically differ from one. This result is confirmed by the $\chi^{2}$-test which does not reject constant returns to scale (CRS) at a significance level of $15 \%$ (see the third column of Table 4$)^{18}$. Besides, even if the flow of new relief jobs increases the number of hirings $(\pi=0.10)$, it does not affect it significantly (see the fourth column of Table 4$)^{19}$.

Since we cannot reject these restrictions, we choose to discuss the parameter estimates on the basis of the regression model (21) on which we impose: $\forall i \in\{1,2,3\}: v_{\text {in }}^{C}=$ $0, \alpha+\beta=1$ and $\pi=0$. Imposing CRS will also allow a better comparison with other empirical studies which directly set this restriction (as in Van Ours and Ridder 1995). The results are reported in the first column of Table 5. The estimated elasticity of matches with respect to unemployment and vacancies is respectively 0.37 and 0.63 . Using the flow of hirings as dependent variable, Van Ours and Ridder (1995) estimate similar matching elasticities in a model allowing for job competition. The elasticity on unemployment is generally higher (of the order of 0.7 ) in studies estimating traditional matching function at the aggregate level with the flow from unemployment as dependent variable (see Petrongolo and Pissarides 2001).

\section{INSERT TABLE 5 APPROXIMATELY HERE}

Note that the probability of being matched decreases markedly with unemployment duration. Besides, workers aged between 29 and 44 years old are significantly less likely of being hired than younger workers: The exit rate of prime-aged men is $23 \%$ ( $=1-$ $\exp (-0.26))$ lower than the one of young men $^{20}$.

\footnotetext{
${ }^{18}$ The unconstrained model of this test is the regression model $(21)$ with $\forall i \in\{1,2,3\}: v_{i n}^{C}=0$, in the second column of Table 4 .

${ }^{19}$ idem.

${ }^{20}$ We also estimated our (restricted) regression model for young people only. We conclude that only the matching elasticities differ between these two models $(\hat{\beta}=0.75$ for men aged $<=28)$. In particular, the job competition and vacancy parameters are similar to those obtained for the whole population. Estimation results are available upon request.
} 
Finally, consider the performance of our regression model on the basis of the goodnessof-fit statistic. The model is not rejected against the saturated model ( $\mathrm{P}$-value $=47 \%)$. Note also that the standard deviation of the specification errors, $\varepsilon_{a k \tau}^{i}$, is of the order of .10 for the different schooling groups. For the highest education level $(i=4)$, the specification error accounts for only $3 \%$ of the variation in the dependent variable while it contributes to a more important variation for the lower schooling levels (about 10\%). Since the determinants of the exit rate by schooling level are inter-related in case of job competition, specification errors are correlated. As expected, the correlation is particularly large between adjacent education levels.

\subsection{Job competition and vacancy parameters}

The first column of Table 2 indicates that there is significant job competition at each schooling level, and that its extent increases markedly with the educational attainment of the worker. On average over the observation period, $\kappa^{4}=6$ while $\kappa^{3}=1.5$ and $\kappa^{2}=0.4$. Since $\kappa^{i}>1$ for $i=3,4$, the overeducated job seekers with these schooling levels are more likely to be hired than those of have just the required level, i.e. $z^{i}>1$ for $i=3,4$. The $\kappa^{4}$ parameter is so high that we cannot exclude that all unemployed workers with higher education search for jobs normally filled by workers with an upper secondary degree (i.e. $\lambda^{4}=1$ ). In this competition for jobs, there are by far preferred to those who have just the required schooling level.

Table 2: Average value of the job competition parameters and \% of overeducated

\begin{tabular}{ccc}
\hline & $\kappa^{i}$ & $\frac{F_{i}^{i+1}}{F_{i}}$ \\
\hline Higher education $(i=4)$ & $6.04[3.19,11.43]$ & \\
\hline Upper secondary $(i=3)$ & $1.55[1.10,2.18]$ & 0.76 \\
\hline Lower secondary $(i=2)$ & $0.43[0.28,0.64]$ & 0.47 \\
\hline No education or elementary school $(i=1)$ & - & 0.26 \\
\hline Weighted average $\left(\frac{\sum_{i=1}^{3} F_{i}^{i+1}}{\sum_{i=1}^{3} F_{i}}\right)$ & & 0.43 \\
\hline
\end{tabular}

Note: Between [.], 95\% confidence interval. 
An alternative measure of job competition is the estimated share of hirings filled by overeducated workers at each level of education (see the second column of Table 2). This measure is the one which is traditionally reported in the overeducation literature. We find that on average, $43 \%$ of dismissed workers who find a new job are overeducated for the job. The fraction is particularly high for jobs requiring an upper secondary degree.

As expected, we reject a specification without job competition, i.e. $\forall i, \tau: \kappa_{\tau}^{i}=0$, according to the $\chi^{2}$-test (see the second column of Table 5). Even if the job competition parameter is relatively small at the lower secondary level, we also clearly reject the absence of job competition between workers with a lower secondary degree and those with at most an elementary degree according to the $\chi^{2}$-test (see the third column of Table 5). These results differ markedly from Van Ours and Ridder (1995). They found evidence of significant job competition only at the top segment of the labour market, between workers with a higher vocational degree and academically educated workers. These workers share the same schooling group in our analysis.

\section{INSERT FIGURE 6 APPROXIMATELY HERE}

Finally, job competition appears to be countercyclical in Wallonia, as observed in comparing a Belgian business cycle indicator ${ }^{21}$ (the Kredietbank indicator) and the estimated second degree polynomial function in Figure 6. The extent of job competition increases significantly with the strong deterioration of the economic conditions from 1991. Gautier et al. (2002) found evidence of countercyclical job competition at only one of the lower job complexity levels: At this level, the difference between average schooling of the inflow and the outflow (at the firm level) increases in downturn.

Table 3: Average value of the vacancy and tightness parameters

\begin{tabular}{ccc}
\hline & $\frac{V_{i}}{V_{1}}$ & $\frac{\tilde{\theta}_{i}}{\tilde{\theta}_{1}}$ \\
\hline Higher education $(i=4)$ & $0.01[0.00,0.05]$ & $0.03[0.01,0.42]$ \\
\hline Upper secondary $(i=3)$ & $0.27[0.14,0.49]$ & $0.51[0.21,1.23]$ \\
\hline Lower secondary $(i=2)$ & $0.76[0.53,1.10]$ & $0.78[0.56,1.13]$ \\
\hline No education or elementary school $(i=1)$ & - & 1 \\
\hline
\end{tabular}

Note: Between [.], 95\% confidence interval.

\footnotetext{
${ }^{21}$ There is no regional business cycle indicator in Belgium.
} 
As regards the distribution of job offers by educational level, the estimated $v_{4}$ parameter indicates that there are almost no job offers for the unemployed with higher education. The first column of Table 3 gives the average estimated value $V_{i c}$ with respect to its value in the segment requiring at most an elementary degree $(i=1)$. While 100 are opened for workers with almost no education, only 1 is posted for workers who completed higher education with a $95 \%$ confidence interval equal to $[0,5]^{22}$. For the other segments, the number of job offers decreases with the required schooling level.

\section{INSERT TABLE 6 APPROXIMATELY HERE}

The $\chi^{2}$-test shows that the $v_{2}$ parameter does not differ significantly from the $v_{1}$ parameter on average and over seasons (see the second column of Table 6). Besides, we cannot reject that the seasonal variation in $v_{3}$ and $v_{4}$ is the same ${ }^{23}$ (see the third column of Table 6). The estimated series of job offers at the highest schooling level also presents some significant cyclical variation. At the beginning of the period, there is merely no jobs proposed to the highest educated unemployed workers. When the economic conditions deteriorate in 1992, they receive some job offers. This result explains partly why the exit probability of the highest educated workers was less affected by the recession in 1993 than the one of the other schooling groups (see Figure 3).

Finally, we can also evaluate the extent of mismatch between the labour demand and supply by educational level among the unemployed population that we consider. To that purpose, we specify a model in which we estimate directly tightness indicators, $\tilde{\theta}_{i c}$ given in (2), rather than vacancy parameters ${ }^{24}$. The second column of Table 3 reports the average estimated value $\tilde{\theta}_{i c}$ with respect to its value in the segment requiring at most an elementary degree $(i=1)$. Although their confidence interval is relatively large, the $\mathrm{V}-\mathrm{U}$ ratios decrease from the lowest to the highest segments of the labour market. If we take into account the supply of skills, we conclude that there is a relative shortage of job offers requiring a diploma of higher education, and to a lesser extent for those requiring an upper secondary degree, for dismissed workers in Wallonia ${ }^{25}$.

\footnotetext{
${ }^{22}$ The asymmetry of the confidence interval is explained by the fact the parameter $v_{i 0}$ and its standard deviation are the arguments of an exponential function (see (15)).

${ }^{23}$ The seasonal coefficients of the $v_{i}$ parameters must be interpreted as the specific variation of the job offers by schooling level through seasons beyond the common seasonality observed in $V_{c}$.

${ }^{24}$ The estimation results are available upon request.

${ }^{25}$ According to a $\chi^{2}$-test, we cannot reject a similar V-U ratio in the two lowest segments of the labour market $(i=1,2)$ at a signifiance level of $6.8 \%$. The V-U ratios in the upper segments of the labour market $(i=3,4)$ are significantly lower from the one estimated in the bottom segments $(\mathrm{P}$-value $=0.6 \%)$.
} 


\subsection{Interpretation of the results}

We now turn to the interpretation of the parameter estimates. How could we first explain the importance of job competition among the unemployed workers in Wallonia? This region is characterised by a structural weakness of job creation since the mid eighties. Over the 1984-1995 period, employment increased by 7.6\% in Wallonia while it rose by almost 20\% in Flanders (see Sneessens et al. 1999). In comparison with the employment performances of our bordering countries during this period, those registered in the Walloon region are very bad. For the period that we consider, the employment growth in Wallonia was further hampered by the strong deterioration of the economic prospects observed in all European countries. The relative scarcity of jobs in Wallonia certainly induced dismissed workers to extend job search on the skill segment below their own, thereby crowding out lower educated unemployed in their own segments. This process was at its height in the economic trough of 1993 (see Figure 6).

Why then does tightness decrease with the level of education and, particularly, why is it so low for the highest level of education? In order to understand this finding, note that the analysis only retains unemployed job seekers who separated from their employers and who did not directly find a new job. Therefore, our estimation of vacancies by schooling level concerns only those intended to this selective population, which excludes young school leavers and employed job seekers. Below, we argue that the fraction of vacancies addressed to these groups as opposed to unemployed workers increases with the level of education, particularly in a depressed labour market. As a result, the extent of job competition between unemployed workers rises with their schooling achievement.

The first argument relates to supply side factors. The share of high educated workers is larger among employed job seekers and school leavers than among unemployed workers. On-the-job search is indeed more prevalent in the upper segments of the labour market where labour mobility is important. Moreover, the share of students who leave school with higher education is nowadays relatively large: In the early nineties, $33.4 \%$ of a cohort of young children achieved this level in the French-speaking education, against $29.6 \%$ and $37 \%$ who attained at most an upper and a lower secondary degree respectively (see Dal and Dupierreux 1996). Given the abundant supply of high-skilled job seekers and the depressive economic context, jobs requiring higher education will be predominantly addressed to other types of job seekers than unemployed dismissed workers ${ }^{26}$.

\footnotetext{
${ }^{26}$ One could alternatively argue that $v_{i}$ is not the 'share' of jobs intented to unemployed dismissed workers, but a reduced form of a vacancy parameter, common to all job-seekers in segment $i$, and a com-
} 
The relatively low number of jobs offered to the high-skilled unemployed can also be justified by a demand side argument. For the employers, being jobless is a signal of low productivity, particularly for the more educated workers who face a lower risk of unemployment. Moreover, highly educated dismissed workers signal 'bad quality' by claiming unemployment benefits after dismissal: It implies that one did not find another job during the preceding notice period ${ }^{27}$. This argument does not hold for less educated workers since notice periods are much shorter for these groups ${ }^{28}$.

Finally, how could we explain that for the jobs requiring an upper secondary degree, the unemployed workers with higher education are much more likely to be hired than those who have just the required schooling level? In comparison with our bordering countries and with Flanders, the distribution of young people by level of educational attainment has a particular feature in Wallonia: This region is characterised by a relatively large number of high school graduates, but also by a relatively low number of young people who achieve an upper secondary degree (see Binon et al. 1998). This scarcity of graduates mainly concerns the vocational and technical degrees ${ }^{29}$. In a context of skill biased technological change, employers may then be inclined to hire more educated workers on jobs normally filled by workers with a technical degree of the upper secondary school. Note that a large majority of unemployed workers with higher education have a vocational or technical degree of three years at the latest $(60 \%)^{30}$.

\subsection{Decomposition of the exit rate by schooling level}

In order to improve our understanding of the results, we decompose the determinants of the estimated hiring rate by schooling level. We take the average value of our estimates petition process between unemployed dismissed workers and other types of job searchers (denoted by $O^{i}$ ). At the highest schooling level, this interpretation would imply that (with CRS): $v_{4}=v_{4}^{*}\left(U^{4}+\kappa_{*}^{4} O^{4}\right)^{-1}$. However, the conclusion remains the same: in a context of depressed labour market and abundant supply of highly educated job seekers, jobs requiring high skills are rarely filled by unemployed dismissed workers.

${ }^{27}$ Note that for Belgium, the average quality of entrants into unemployment improves during recessions and falls in upturns (see Dejemeppe and Saks 2002). This could explain why employers propose some jobs to the high skilled unemployed workers when the economic conditions deteriorate.

${ }^{28}$ The educational level is correlated with the wage level and the professional status (worker or employee) determining the length of notice periods in Belgium.

${ }^{29}$ Students with a general degree are more likely to enrol to higher education (see Dal and Dupierreux 1996), whose access is relatively easy in Belgium in comparison with other European countries.

${ }^{30}$ This figure is obtained from the monthly reports of the public employment agency (ONEm) and is an average over our observation period. 
and regressors (see the first column of Table 5 in Appendix 5 ) and set $e_{a k}=1$. This yields the following decomposition of $\hat{h}^{i}$ by schooling level, where $\hat{\beta}=0.63, \hat{S}_{i}=\tilde{U}^{i}+\hat{\kappa}^{i+1} \tilde{U}^{i+1}$ and the figure in bold refers to the value of $\hat{h}^{i}$. when setting $\forall i: \hat{\kappa}^{i}=0$ :

Higher education $(i=4)$ :

$$
\underbrace{\hat{h}^{4}}_{0.70}=\underbrace{(\underbrace{\tilde{\theta}_{4}}_{0.01})^{\hat{\beta}}}_{0.04}+\underbrace{\hat{\kappa}^{4}}_{6.04} \underbrace{(\underbrace{\tilde{\theta}_{3}}_{0.13})^{\hat{\beta}}(\underbrace{\frac{\tilde{U}^{3}}{\hat{S}_{3}}}_{0.24})^{\hat{\beta}}}_{0.11}
$$

Upper secondary $(i=3)$ :

$$
=\underbrace{(\underbrace{\tilde{\theta}_{3}}_{0.13})^{\hat{\beta}}(\underbrace{\frac{\tilde{U}^{3}}{\hat{S}_{3}}}_{0.24})^{\hat{\beta}}}_{0.11}+\underbrace{\hat{\kappa}^{3}}_{1.55} \underbrace{(\underbrace{\tilde{\theta}_{2}}_{0.22})^{\hat{\beta}}(\underbrace{\frac{\tilde{U}^{2}}{\hat{S}_{2}}}_{0.53})^{\hat{\beta}}}_{0.26}
$$

Lower secondary $(i=2)$ :

$$
\underbrace{\hat{h}^{2}}_{\substack{0.40 \\ \hat{\kappa}^{2}=0: 0.39}}=\underbrace{(\underbrace{\tilde{\theta}_{2}}_{0.22})^{\hat{\beta}}(\underbrace{\frac{\tilde{U}^{2}}{\hat{S}_{2}}}_{0.53})^{\hat{\beta}}}_{0.26}+\underbrace{\hat{\kappa}^{2}}_{0.43} \underbrace{(\underbrace{\tilde{\theta}_{1}}_{0.26})^{\hat{\beta}}(\underbrace{\frac{\tilde{U}^{1}}{\hat{S}_{1}}}_{0.74})^{\hat{\beta}}}_{0.35}
$$

Primary or no education $(i=1)$ :

$$
\underbrace{\hat{h}^{1}}_{0.35}=\underbrace{(\underbrace{\tilde{\theta}_{1}}_{0.26})^{\hat{\beta}}(\underbrace{\frac{\tilde{U}^{1}}{\hat{S}_{1}}}_{0.74})^{\hat{\beta}}}_{0.35}
$$

Unemployed workers who completed higher education have a large outflow rate (on average, 0.70) due to the strong competition they exert on the jobs normally filled by 
those with an upper secondary degree. They compensate the lack of job offers for their services by searching for jobs in the lower segment. In this competition for jobs, there are by far preferred to those who have just the required schooling level. If they had no access to jobs requiring an upper secondary degree, the exit rate of workers with higher education would only be 0.04. Competition from higher educated workers reduces the hiring rate of unemployed workers with an upper secondary degree on their own segment: Their hiring rate falls to 0.11 instead of 0.28 in the absence of job competition. However, they can more than compensate for this negative effect by competing for jobs at the lower secondary level. This raises their exit rate from 0.11 to 0.51 .

For the same reasons than their more educated counterparts, some unemployed workers with a lower secondary degree offer their work at the bottom of the ladder. Even if their competition is not very strong as compared to the competition they face from the higher educated workers, the outflow rate of workers with a lower secondary degree is relatively high, on average 0.40 , due to a relative large number of job offers in their own segment. The net effect of job competition on their exit rate is close to zero since it would be set to 0.39 otherwise. The outflow rate of the lowest educated is negatively affected by the search behaviour of the workers with a lower secondary degree: Their exit rate equals to 0.35 and 0.43 with and without job competition respectively.

This decomposition analysis indicates that only job competition explains the increase in the transition rate out of unemployment with the level of education for dismissed workers. The ranking of the exit rates by schooling level would be reversed without competition, since the number of job offers strongly decreases with the schooling level.

\section{Conclusion and policy recommendations}

In this paper, we evaluated the extent of crowding out among unemployed dismissed workers in Wallonia (Belgium) for the period June 1989 - February 1994. We estimated the structural parameters of a matching function generalised to incorporate crowding out effects on the basis of flow data from unemployment containing information on the level of educational attainment of the worker, but not on the level of schooling required by the employer for the job. We therefore avoided bias induced by the mismatch between the measurement of educational attainment at the supply side and the demand side of the labour market. In addition, the relative distribution of vacancies by schooling level was estimated rather than being based on reported educational requirements. 
We found that there is significant job competition among unemployed dismissed workers in Wallonia. On average, $43 \%$ of dismissed workers who find a new job are overeducated. The estimated share of hirings filled by overeducated workers is particularly high for jobs normally requiring an upper secondary degree. We claim that the scarcity of jobs in Wallonia during the early nineties mainly accounts for this intense job competition.

Our results also indicated that almost no jobs are offered to the higher educated dismissed workers. In addition, the number of vacancies requiring an upper secondary degree is significantly smaller than the job offers at the lower levels of education. Even if we take into account the supply of skills, we must conclude that among unemployed workers in Wallonia, there is a relative shortage of job offers requiring a diploma of higher education, and to a lesser extent of those requiring an upper secondary degree.

In order to understand these findings, note that the analysis only retains unemployed job seekers with some labour market experience. It neglects unemployed school-leavers and searchers on-the-job. We argued that in a context of depressed labour market and abundant supply of highly educated job seekers, vacancies requiring higher education are predominantly addressed to the latter groups and not to dismissed workers. As a result, these workers exert an intense job competition on the lower segments.

Since we estimate the demand for skills of a particular population of job seekers, our results are not inconsistent with skill biased technological change. The excess demand for higher skills could be limited to the group of school leavers and searchers on-the-job. Still, our results question the interpretation of mismatch indicators. All measures are built on models ignoring the mobility of workers between segments of the labour market, i.e. crowding out (see for Belgium, Sneessens et al. 1999; for France, Sneessens and ShadmanMehta 1995; for the United Kingdom, Jackman et al. 1990; for other countries, including UK, Manacorda and Petrongolo 1999). As an example, the mismatch index of Sneessens et al. (1999) is the ratio of skilled to total employment rates, skilled employment being measured by the share of highly educated people in the working population. According to this ratio, there has been a growing imbalance between the demand and the supply of skills from the late seventies and up to the mid eighties in Belgium, mainly in Wallonia. Our results suggest that this increase could partly reflect a more intense crowding out of lower educated workers by higher educated ones.

From our results, one could expect that the vitality of employment growth in the recent years up to 2001 lowers the extent of job competition among the unemployed 
population in Wallonia. This evolution remains to be confirmed. However, given the structural weakness of job creation in the Walloon region, it is unlikely that the recent economic growth will be sufficient to significantly reduce job competition. Structural policies are therefore called for to stimulate long-term employment growth.

Among these policies, one should not exclude improvements in the regular educational system and training programmes. This statement challenges the typical view on the policy implications of job competition. Indeed, it is often argued that such policies are inefficient when job competition exists, since they would only reinforce this process and waste further productive resources (see e.g. Borghans and de Grip 2000). However, this view is based on a static line of arguments. According to some authors (see e.g. Binon et al. 1998), insufficient attention to education and training programmes in Wallonia contributed to hamper the development of new activities after the de-industrialisation shock of the late seventies. By enhancing human capital and the growth capacity of Wallonia, these schemes can therefore help to reduce the extent of unemployment, and thereby job competition. In addition, in view of the scarcity of graduates in vocational and technical degrees at the upper secondary schooling level (attained after 12 years of schooling), it may be wise to focus programmes on this skill segment. 


\section{References}

Abbring, J.H., G.J. van den Berg, and J.C. van Ours (2001), "Business cycles and compositional variation in U.S. unemployment", Journal of Business and Economic Statistics, 19 (4), 436-448.

Albrecht, J., G. van den Berg, and S. Vroman (2002), "The equilibrium effects of a major training program", Mimeo, Georgetown University and Vrije Universiteit Amsterdam.

Albrecht, J. and S. Vroman (2001), "A matching model with endogeneous skill requirements", forthcoming in International Economic Review.

Amemiya, T. (1981), "Qualitative response models: A survey", Journal of Economic Literature, 19, 1483-1536.

Amemiya, T. and F. Nold (1975), "A modified logit model", Review of Economics and Statistics, 57, 255-57.

Autor, D.H., L.F. Katz, and A.B. Krueger (1998), "Computing inequality : Have computers changed the labour market ?", Quarterly Journal of Economics, 113, 11691213.

Berkson, J. (1944), "Application of the logistic function to bio-assay", Journal of the American Statistical Association, 39, 357-365.

Berman, E., J. Bound, and S. Machin (1998), "Implications of skill-biased technological change : international evidence", Quarterly Journal of Economics, 113, 1245-1279.

Binon, F., J.-B. Charles, R. Deschamps, S. Delaigle, J.-C. Jacquemin, O. Lohest, M. Mignolet, H.R. Sneessens, and B. Van der Linden (1998), "Recherche relative aux facteurs explicatifs de l'évolution de l'emploi en Wallonie et de la divergence interrégionale pour la période 1974-1995", Rapport au Ministre wallon du Budget et Finances, Emploi et Formation J.-C. Van Cauwenberghe, IRES (UCL) et CREW (FUNDP).

Borghans, L. and A. de Grip (2000), The overeducated worker? The economics of skill utilization, Edward Elgar, Cheltenham, UK.

Broersma, L. and J.C. van Ours (1998), "Job searchers, job matches and the elasticity of matching", Labour Economics, 6 (1), 77-93.

Cockx, B. (1997), "Analysis of transition data by the minimum chi-square method: an application to welfare spells in Belgium", The Review of Economics and Statistics, 79 (3), 392-405.

Cockx, B. and G. Ridder (2001), "Social employment of welfare recipients in Belgium: 
An evaluation", The Economic Journal, 111, 471, 1-31.

Coles, M.G. and B. Petrongolo, "A test between unemployment theories using matching data”, CEPR Discussion Paper №3241, Centre for Economic Policy Research, London.

Coles, M.G. and E. Smith (1998), "Marketplaces and matching", International Economic Review, 39, 239-254.

Dal, L. and J.M. Dupierreux (1996), Analyse descriptive et modélisation de l'enseignement supérieur non universitaire de la Communauté française de Belgique, Rapport à la Direction Générale de l'Enseignement supérieur de la Recherche Scientifique de la Communauté française de Belgique, UCL, Louvain-la-Neuve et ULB, Bruxelles.

Dejemeppe, M. and Y. Saks (2002), "A new light into regional unemployment disparities in Belgium: Longitudinal analysis of grouped duration data.", IRES Discussion Paper N²002-19, Institut de Recherches Economiques et Sociales, Université catholique de Louvain.

Denolf, L., J. Denys, and P. Simoens (2001), Les entreprises et le recrutement en Belgique en 2000, HIVA, Katholieke Universiteit Leuven.

Dolado, J.J., F. Felgueroso, and J.F. Jimeno (2000), "Youth labour markets in Spain: Education, training and crowding out", European Economic Review, 44, 943-956.

Drèze, J.H. and H.R. Sneessens (1997), "Technological development, competition from low-wage economies and low-skilled unemployment", in Snower and de la Dehesa, pp.75-106.

Flinn, C.J. and J.J. Heckman (1982), "Models for the analysis of labor force dynamics", in Basmann, R. and G. Rhodes (eds.), Advances in Econometrics, 1, 35-95.

FOREM (1995), Enquête sur les sorties d'inscription des demandeurs d'emploi, Service Etudes et Statistique, FOREM.

Gautier, P.A. (2002), "Unemployment and search externalities in a model with heterogeneous jobs and workers", Economica, 69, 21-40.

Gautier, P.A., G.J. van den Berg, J.C. van Ours, and G. Ridder (2002), "Worker turnover at the firm level and crowding out of lower educated workers", European Economic Review, 46 (3), 523-538.

Green, F., S. McIntosh, and A. Vignoles (1999), '"Overeducation' and skills - Clarifying the concepts", Mimeo, Centre for Economic Performance, London School of Economics and Political Science.

Gurgand, M. (1999), "Schooling and unemployment: Is there job-competition on the 
French labor market?", Mimeo, Centre d'études pour l'emploi and CREST, Paris.

Hartog, J. (2000), "Over-education and earnings : where are we, where should we go?", Economics of Education Review, 19, 131-147.

Haskel, J. and R. Jackman (1988), "Long-term unemployment in Britain and the effect of the Community Programme", Oxford Bulletin of Economics and Statistics, 50, 379-408.

Jackman R., R. Layard, and C. Pissarides (1989), "On vacancies", Oxford Bulletin of Economics and Statistics, 51, 4, 377-394.

Jackman, R., R. Layard, and S. Savouri (1990), "Labor-market mismatch : A framework or thought", in Padoa-Schioppa, F. ed., Mismatch and Labor Mobility, Cambridge University Press.

Machin, S. and J. Van Reenen (1998), "Technology and changes in skill structure : Evidence from seven OECD countries", Quarterly Journal of Economics, 113, 1215-1244.

Manacorda , M. and B. Petrongolo (1999), "Skill mismatch and unemployment in OECD countries", Economica, 66, 181-207.

OECD (1997a), Education at the Glance, OECD, Paris.

OECD (1997b), The public employment service: Belgium. OECD, Paris.

Petrongolo, B. and C.A. Pissarides (2001), "Looking into the black box: A survey of the matching function", Journal of Economic Literature, 39 (2), 390-431.

Sneessens, H.R., R. Nicolini, et F. Shadman-Mehta (1999), "Innovation et chômage en région wallonne : aspects économiques", dans Des idées et des hommes : pour construire l'avenir de la Wallonie et de Bruxelles, Academia-Bruylant.

Sneessens, H.R. and Shadman-Mehta F. (1995), "Real wage, skill mismatch and unemployment persistence, France, 1962-89", Annales d'Economie et de Statistique, 37/38, 255-293.

Teulings, C.N. and P.A. Gautier (2000), "The right man for the job. Increasing returns in search?", Mimeo, Erasmus University Rotterdam and Tinbergen Institute Amsterdam.

Van Hoof, K. (1996), "Is er verdringing op de Vlaamse arbeidsmarkt ?", Steunpunt WAV, Nieuwsbrief 3.

Van Ours, J.C. and G. Ridder (1995), "Job matching and job competition: Are the lower educated at the back of the job queues?", European Economic Review, 39, $1717-1731$. 


\section{$8 \quad$ Figures and Tables}

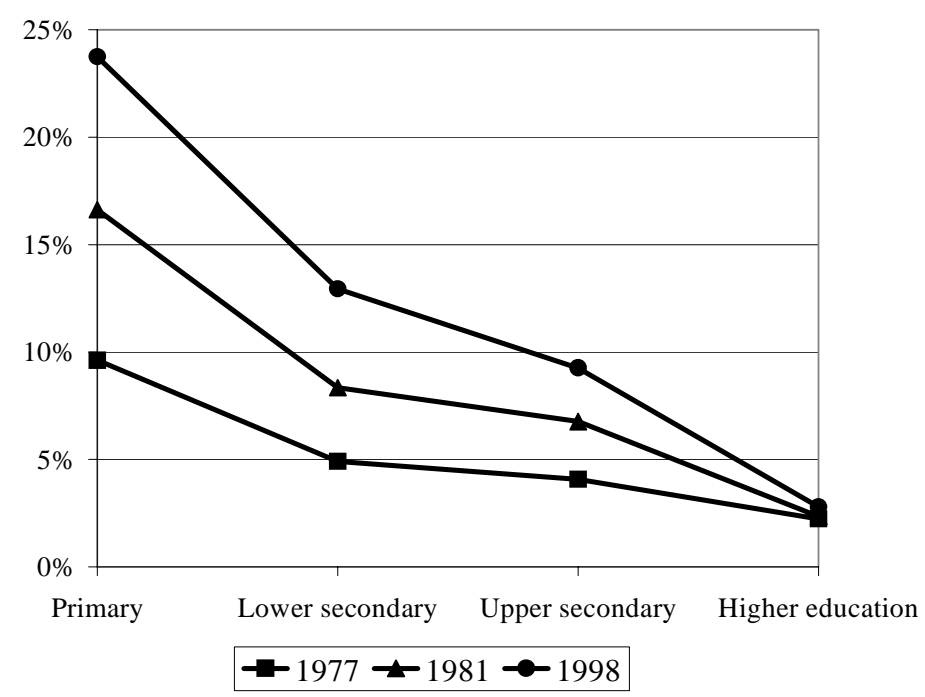

Figure 1: Unemployment rate by level of education in Belgium

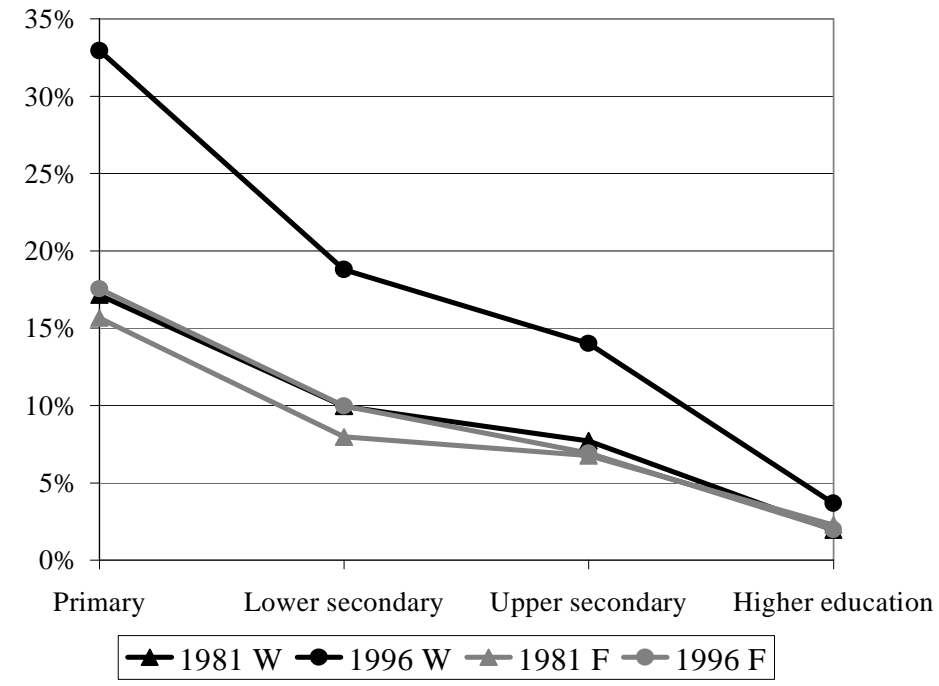

Figure 2: Unemployment rate by level of education in Wallonia (W) and Flanders (F) 


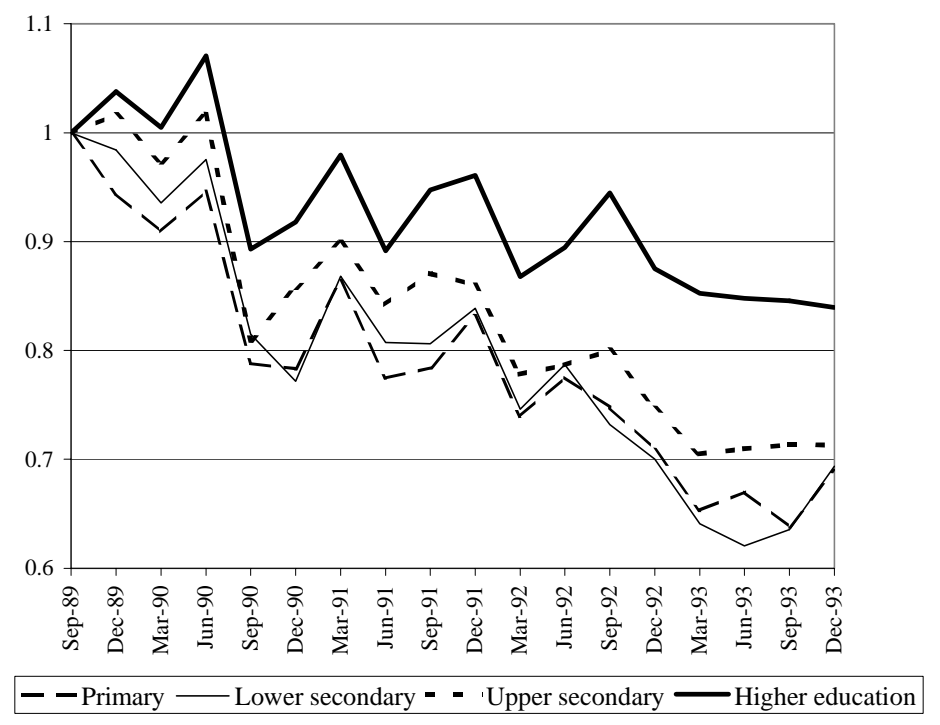

Figure 3: Cyclical dependence of the empirical outflow probability by level of education

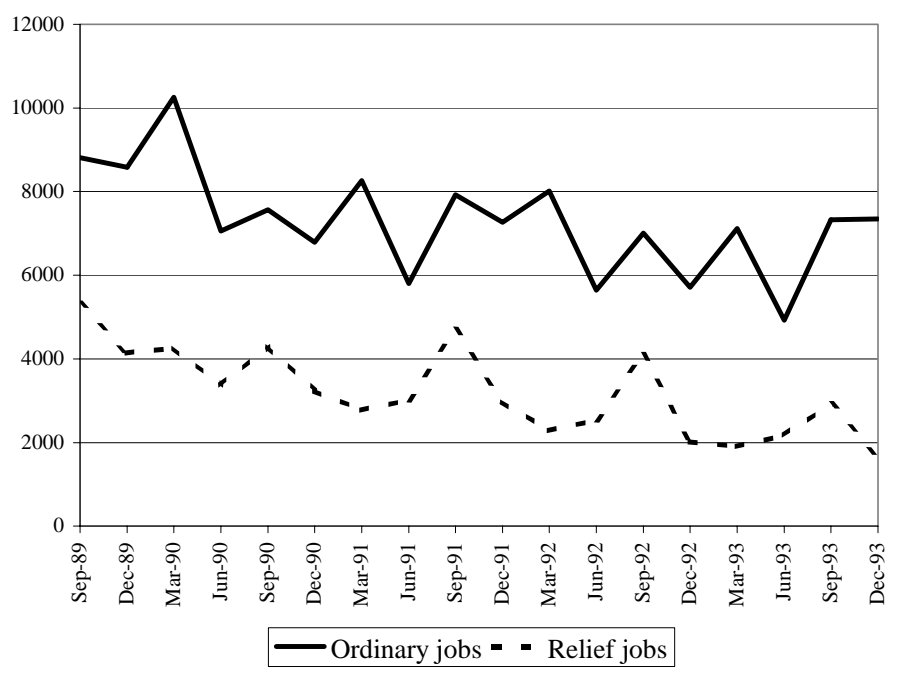

Figure 4: Flow of job offers at the Public Employment Agency 


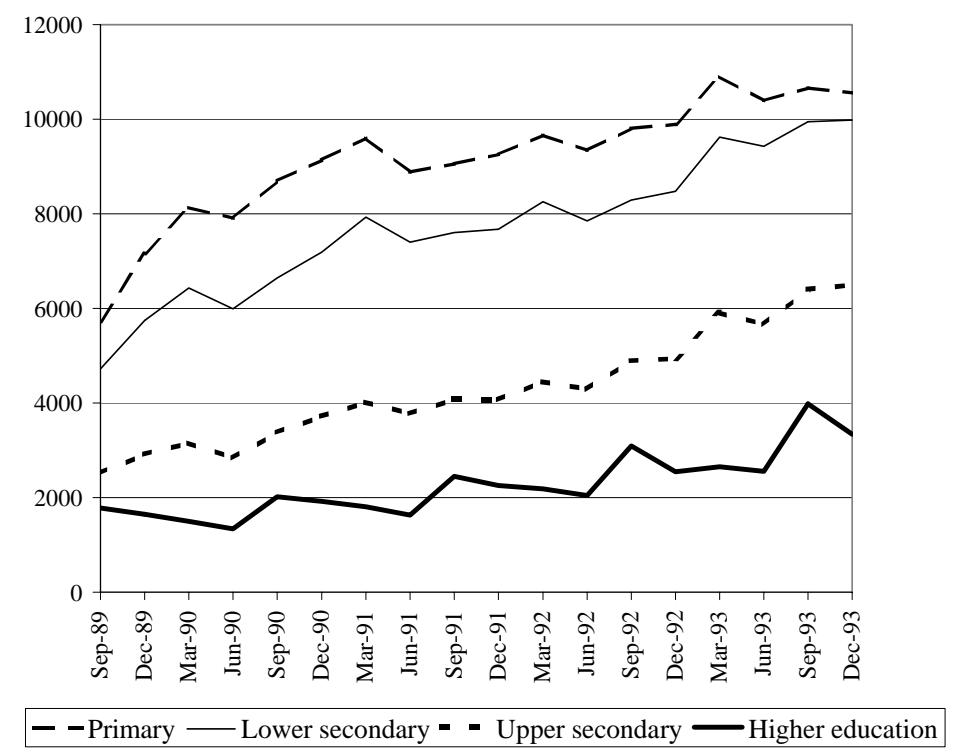

Figure 5: Short-term unemployment by level of education

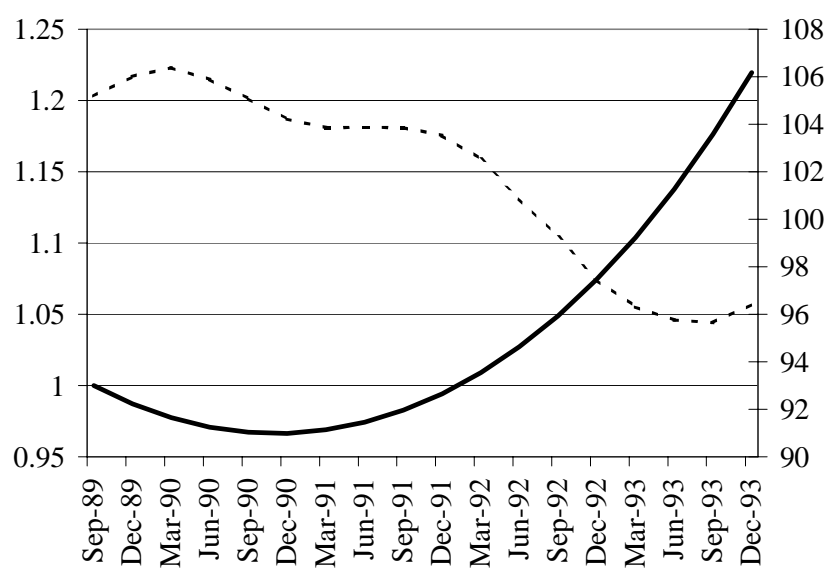

- Job competition -.. Kredietbank indicator

Figure 6: Cyclical job competition and the Kredietbank indicator (right scale) 
Table 4: Hazard model estimates and specification tests

\begin{tabular}{|c|c|c|c|c|c|c|c|c|}
\hline Variables & & $\mathrm{SD}$ & $\begin{array}{l}v^{C}{ }_{i n}=\mathbf{0} \\
(\mathbf{i}=\mathbf{1}, \mathbf{2 , 3})\end{array}$ & $\mathrm{SD}$ & $\alpha+\beta=1$ & $\mathrm{SD}$ & $\pi=0$ & $\mathrm{SD}$ \\
\hline \multicolumn{9}{|l|}{ 1. Matching elasticities } \\
\hline$\beta$ & 0.73 & 0.13 & 0.81 & 0.12 & 0.66 & 0.05 & 0.63 & 0.04 \\
\hline$\alpha$ & 0.62 & 0.25 & 0.52 & 0.14 & 0.34 & & 0.37 & \\
\hline$\pi$ & 0.18 & 0.40 & 0.10 & 0.27 & -0.19 & 0.20 & 0.00 & \\
\hline \multicolumn{9}{|l|}{ 2. Matching efficiency } \\
\hline \multicolumn{9}{|l|}{ Duration (in quarters) } \\
\hline$\gamma_{2}$ & -0.24 & 0.02 & -0.24 & 0.02 & -0.24 & 0.02 & -0.24 & 0.02 \\
\hline$\gamma_{3}$ & -0.40 & 0.02 & -0.41 & 0.02 & -0.40 & 0.02 & -0.40 & 0.02 \\
\hline$\gamma_{4}$ & -0.57 & 0.02 & -0.57 & 0.02 & -0.57 & 0.02 & -0.57 & 0.02 \\
\hline Age (aged 29-44 years old) & & & & & & & & \\
\hline$\eta_{2}$ & -0.26 & 0.02 & -0.26 & 0.02 & -0.25 & 0.02 & -0.26 & 0.02 \\
\hline \multicolumn{9}{|l|}{ 3. Vacancy parameters } \\
\hline \multicolumn{9}{|l|}{ Primary $\left(v_{1 \tau}\right)$} \\
\hline constant & -5.60 & 3.23 & -4.82 & 2.08 & -1.30 & 0.21 & -1.46 & 0.12 \\
\hline winter & -0.25 & 0.10 & -0.22 & 0.07 & -0.33 & 0.06 & -0.31 & 0.06 \\
\hline spring & 0.14 & 0.10 & 0.11 & 0.06 & 0.09 & 0.08 & 0.15 & 0.05 \\
\hline summer & -0.04 & 0.08 & -0.03 & 0.07 & -0.12 & 0.05 & -0.12 & 0.06 \\
\hline p1 & -0.08 & 0.08 & 0.00 & & 0.00 & & 0.00 & \\
\hline p2 & 0.08 & 0.05 & 0.00 & & 0.00 & & 0.00 & \\
\hline \multicolumn{9}{|l|}{ Lower secondary $\left(v_{2 \tau}\right)$} \\
\hline constant & -6.03 & 3.27 & -5.11 & 2.09 & -1.57 & 0.26 & -1.73 & 0.19 \\
\hline winter & -0.22 & 0.10 & -0.20 & 0.08 & -0.32 & 0.06 & -0.30 & 0.06 \\
\hline spring & 0.12 & 0.10 & 0.08 & 0.07 & 0.05 & 0.08 & 0.11 & 0.06 \\
\hline summer & 0.01 & 0.08 & 0.01 & 0.07 & -0.08 & 0.06 & -0.08 & 0.06 \\
\hline $\mathrm{p} 1$ & 0.10 & 0.14 & 0.00 & & 0.00 & & 0.00 & \\
\hline p2 & -0.15 & 0.11 & 0.00 & & 0.00 & & 0.00 & \\
\hline \multicolumn{9}{|l|}{ Upper secondary $\left(v_{3 \tau}\right)$} \\
\hline constant & -7.00 & 3.31 & -6.01 & 2.05 & -2.57 & 0.39 & -2.78 & 0.34 \\
\hline winter & -0.40 & 0.12 & -0.38 & 0.11 & -0.55 & 0.06 & -0.54 & 0.06 \\
\hline spring & -0.47 & 0.15 & -0.48 & 0.13 & -0.68 & 0.07 & -0.65 & 0.06 \\
\hline summer & -0.74 & 0.24 & -0.70 & 0.20 & -1.03 & 0.09 & -1.05 & 0.09 \\
\hline $\mathrm{p} 1$ & 0.13 & 0.16 & 0.00 & & 0.00 & & 0.00 & \\
\hline $\mathrm{p} 2$ & -0.21 & 0.16 & 0.00 & & 0.00 & & 0.00 & \\
\hline \multicolumn{9}{|l|}{ Higher education $\left(v_{4 \tau}\right)$} \\
\hline constant & -22.40 & 12.38 & -20.71 & 7.75 & -18.58 & 7.18 & -17.74 & 6.53 \\
\hline winter & -1.09 & 0.86 & -1.12 & 0.78 & -2.03 & 0.85 & -1.96 & 0.88 \\
\hline spring & -0.40 & 0.87 & -0.54 & 0.67 & -1.06 & 0.63 & -0.98 & 0.63 \\
\hline summer & -1.36 & 1.26 & -1.05 & 0.98 & -1.64 & 0.91 & -1.83 & 1.00 \\
\hline $\mathrm{p} 1$ & 19.25 & 14.71 & 18.47 & 10.34 & 19.15 & 9.90 & 17.56 & 8.91 \\
\hline p2 & -9.46 & 7.73 & -0.79 & 4.84 & -8.82 & 4.43 & -8.13 & 4.03 \\
\hline
\end{tabular}

Note: In grey, restricted parameters.

(Table continued on next page) 
Table 4: (Continued)

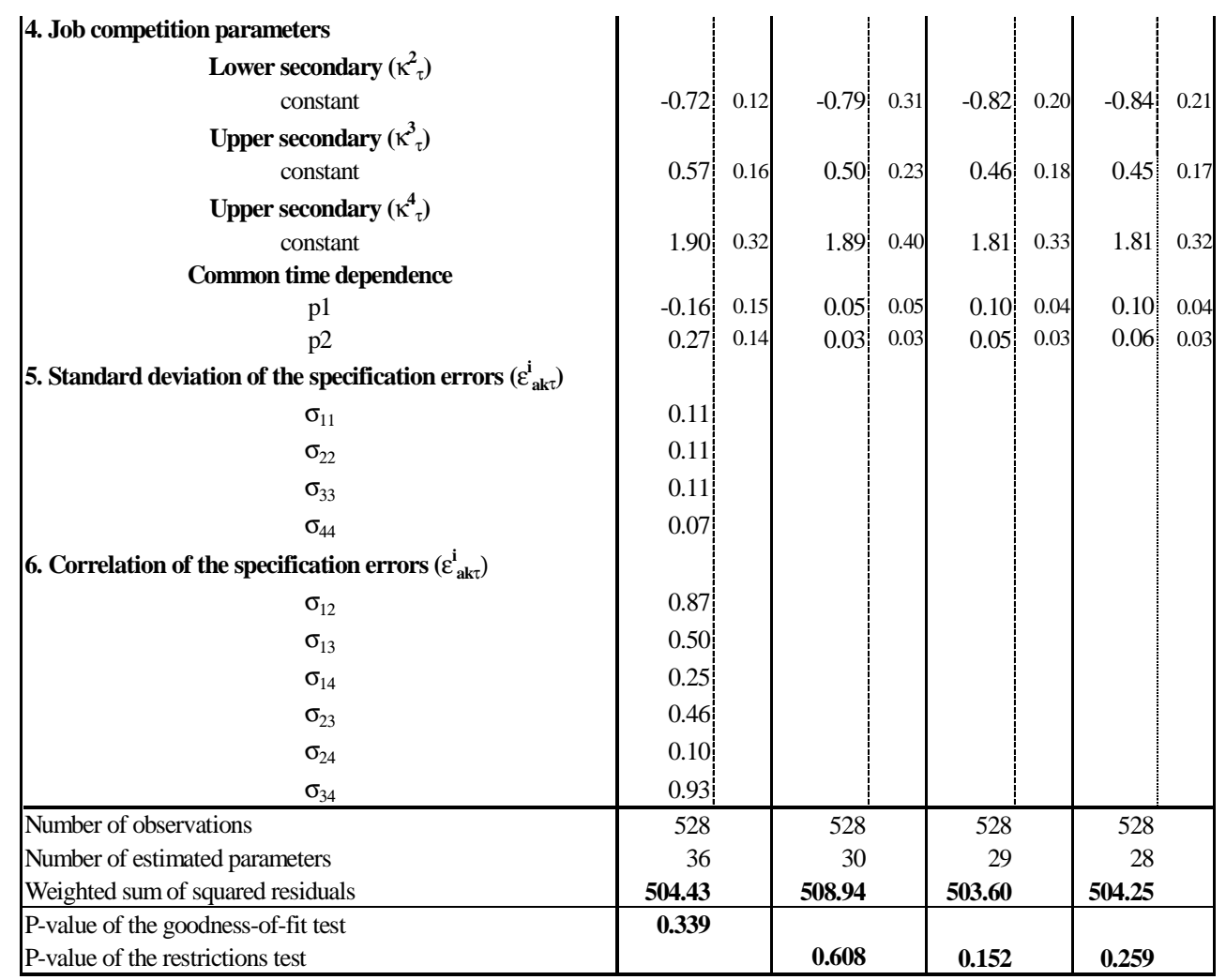


Table 5: Hazard model estimates with restrictions: $\forall i \in\{1,2,3\}: v_{\text {in }}^{C}=0 ; \alpha+\beta=1$; $\pi=0$, and specification tests on the job competition parameters

\begin{tabular}{|c|c|c|c|c|c|c|}
\hline Variables & & $\mathrm{SD}$ & $\kappa_{\tau}^{\mathrm{i}}=\mathbf{0}$ & $\mathrm{SD}$ & $\kappa_{0}^{2}=0$ & $\mathrm{SD}$ \\
\hline \multicolumn{7}{|l|}{ 1. Matching elasticities } \\
\hline$\beta$ & 0.63 & 0.04 & 0.51 & 0.03 & 0.54 & 0.04 \\
\hline$\alpha=1-\beta$ & 0.37 & & 0.49 & & 0.46 & \\
\hline \multicolumn{7}{|l|}{ 2. Matching efficiency } \\
\hline \multicolumn{7}{|l|}{ Duration (in quarters) } \\
\hline$\gamma_{2}$ & -0.24 & 0.02 & -0.24 & 0.02 & -0.24 & 0.02 \\
\hline$\gamma_{3}$ & -0.40 & 0.02 & -0.41 & 0.02 & -0.41 & 0.02 \\
\hline$\gamma_{4}$ & -0.57 & 0.02 & -0.58 & 0.02 & -0.58 & 0.02 \\
\hline Age (aged 29-44 years old) & & & & & & \\
\hline$\eta_{2}$ & -0.26 & 0.02 & -0.25 & 0.02 & -0.26 & 0.02 \\
\hline \multicolumn{7}{|l|}{ 3. Vacancy parameters } \\
\hline \multicolumn{7}{|l|}{$\operatorname{Primary}\left(v_{1 \tau}\right)$} \\
\hline constant & -1.46 & 0.12 & -2.19 & 0.14 & -2.07 & 0.13 \\
\hline winter & -0.31 & 0.06 & -0.42 & 0.07 & -0.37 & 0.07 \\
\hline spring & 0.15 & 0.05 & 0.20 & 0.07 & 0.20 & 0.06 \\
\hline summer & -0.12 & 0.06 & -0.19 & 0.07 & -0.15 & 0.07 \\
\hline \multicolumn{7}{|l|}{ Lower secondary $\left(v_{2 \tau}\right)$} \\
\hline constant & -1.73 & 0.19 & -2.00 & 0.12 & -1.45 & 0.12 \\
\hline winter & -0.30 & 0.06 & -0.46 & 0.07 & -0.38 & 0.06 \\
\hline spring & 0.11 & 0.06 & 0.13 & 0.06 & 0.13 & 0.06 \\
\hline summer & -0.08 & 0.06 & -0.18 & 0.07 & -0.15 & 0.06 \\
\hline \multicolumn{7}{|l|}{ Upper secondary $\left(v_{3 \tau}\right)$} \\
\hline constant & -2.78 & 0.34 & -2.08 & 0.09 & -3.30 & 0.42 \\
\hline winter & -0.54 & 0.06 & -0.33 & 0.07 & -0.60 & 0.08 \\
\hline spring & -0.65 & 0.06 & 0.02 & 0.07 & -0.70 & 0.08 \\
\hline summer & -1.05 & 0.09 & -0.34 & 0.08 & -1.19 & 0.11 \\
\hline \multicolumn{7}{|l|}{ Higher education $\left(v_{4 \tau}\right)$} \\
\hline constant & -18.11 & 6.79 & -2.07 & 0.05 & -16.49 & 4.98 \\
\hline winter & -1.99 & 0.88 & -0.73 & 0.07 & -2.11 & 0.94 \\
\hline spring & -1.00 & 0.64 & -0.80 & 0.06 & -1.12 & 0.63 \\
\hline summer & -1.82 & 1.00 & -1.39 & 0.10 & -2.48 & 1.15 \\
\hline p1 & 18.08 & 9.27 & 0.07 & 0.03 & 15.07 & 6.74 \\
\hline p2 & -8.37 & 4.19 & 0.01 & 0.03 & -6.85 & 2.95 \\
\hline
\end{tabular}

Note: In grey, restricted parameters.

(Table continued on next page) 
Table 5: (Continued)

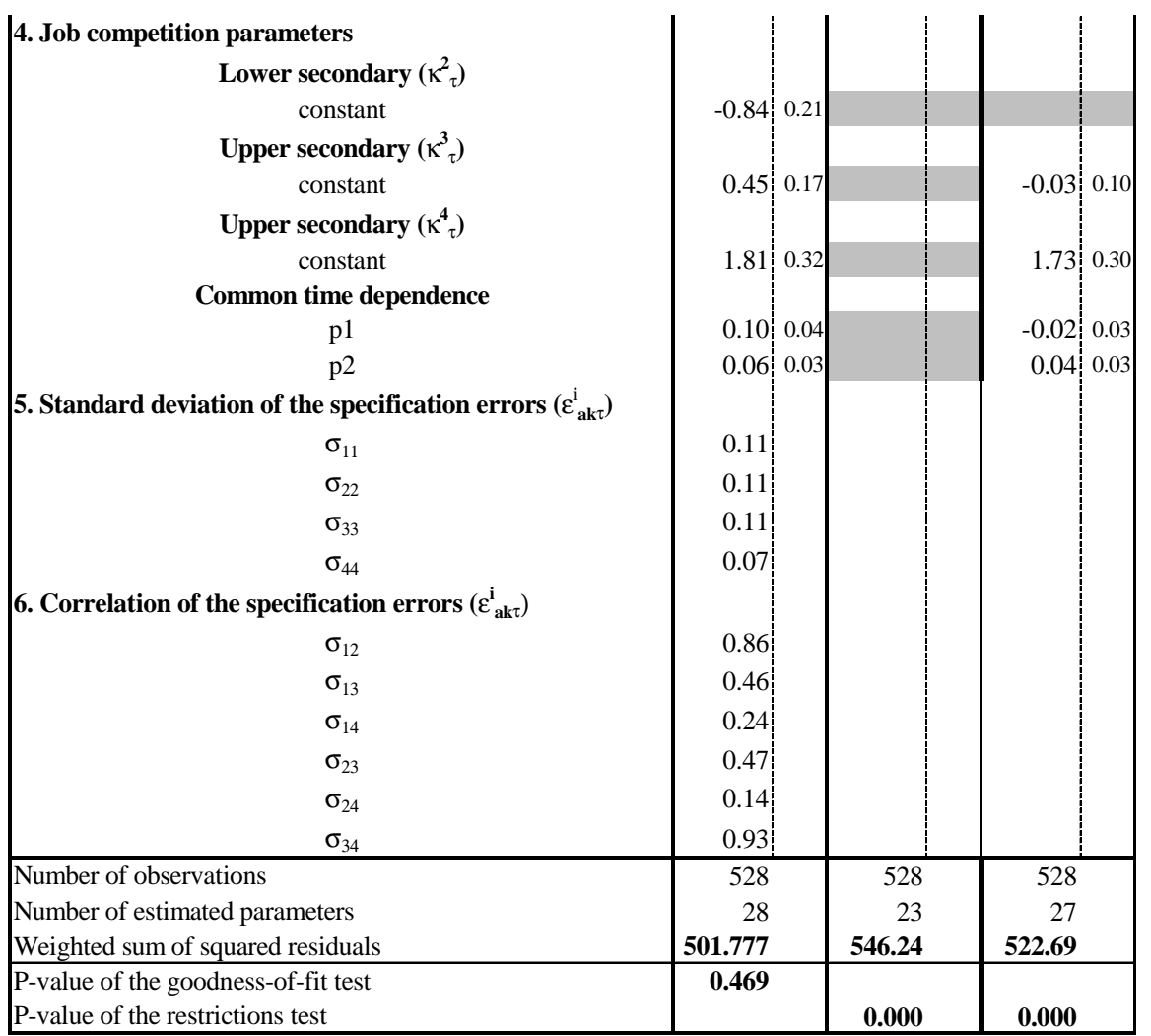


Table 6: Hazard model estimates with restrictions: $\forall i \in\{1,2,3\}: v_{\text {in }}^{C}=0 ; \alpha+\beta=1$; $\pi=0$, and specification tests on the vacancy parameters

\begin{tabular}{|c|c|c|c|c|c|c|}
\hline Variables & & $\mathrm{SD}$ & $v_{1 \tau}=v_{2 \tau}$ & $\mathrm{SD}$ & $v^{S}{ }_{3 \mathrm{~s}}=v^{S}{ }_{4 \mathrm{~s}}$ & SD \\
\hline \multicolumn{7}{|l|}{ 1. Matching elasticities } \\
\hline$\beta$ & 0.63 & 0.04 & 0.63 & 0.04 & 0.63 & $\begin{array}{lll} & 0.04 \\
\end{array}$ \\
\hline$\alpha=1-\beta$ & 0.37 & & 0.37 & & 0.37 & \\
\hline \multicolumn{7}{|l|}{ 2. Matching efficiency } \\
\hline \multicolumn{7}{|l|}{ Duration (in quarters) } \\
\hline$\gamma_{2}$ & -0.24 & 0.02 & -0.24 & 0.02 & -0.24 & 0.02 \\
\hline$\gamma_{3}$ & -0.40 & 0.02 & -0.40 & 0.02 & -0.40 & 0.0 \\
\hline$\gamma_{4}$ & -0.57 & 0.02 & -0.57 & 0.02 & -0.57 & 0.02 \\
\hline Age (aged 29-44 years old) & & & & & & \\
\hline$\eta_{2}$ & -0.26 & 0.02 & -0.26 & 0.02 & -0.26 & 0.02 \\
\hline \multicolumn{7}{|l|}{ 3. Vacancy parameters } \\
\hline \multicolumn{7}{|l|}{$\operatorname{Primary}\left(v_{1 \tau}\right)$} \\
\hline constant & -1.46 & 0.12 & -1.55 & 0.11 & -1.45 & 0.12 \\
\hline winter & -0.31 & 0.06 & -0.31 & 0.05 & -0.31 & $0 . c$ \\
\hline spring & 0.15 & 0.05 & 0.13 & 0.05 & 0.15 & 0.0 \\
\hline summer & -0.12 & 0.06 & -0.10 & 0.05 & -0.12 & 0.06 \\
\hline \multicolumn{7}{|l|}{ Lower secondary $\left(v_{2 \tau}\right)$} \\
\hline constant & -1.73 & 0.19 & -1.55 & & -1.74 & \\
\hline winter & -0.30 & 0.06 & -0.31 & & -0.29 & 0.0 \\
\hline spring & 0.11 & 0.06 & 0.13 & & 0.11 & 0.0 \\
\hline summer & -0.08 & 0.06 & -0.10 & & -0.08 & 0.06 \\
\hline \multicolumn{7}{|l|}{ Upper secondary $\left(v_{3 \tau}\right)$} \\
\hline constant & -2.78 & 0.34 & -2.80 & 0.32 & -2.85 & 0.36 \\
\hline winter & -0.54 & 0.06 & -0.54 & 0.06 & -0.60 & 0.05 \\
\hline spring & -0.65 & 0.06 & -0.65 & 0.06 & -0.67 & 0.0 \\
\hline summer & -1.05 & 0.09 & -1.05 & 0.09 & -1.09 & 0.08 \\
\hline \multicolumn{7}{|l|}{ Higher education $\left(v_{4 \tau}\right)$} \\
\hline constant & -18.11 & 6.79 & -17.38 & 6.10 & -14.88 & 4.98 \\
\hline winter & -1.99 & 0.88 & -1.98 & 0.87 & -0.60 & \\
\hline spring & -1.00 & 0.64 & -0.94 & 0.61 & -0.67 & \\
\hline summer & -1.82 & 1.00 & -1.99 & 1.07 & -1.09 & \\
\hline $\mathrm{p} 1$ & 18.08 & 9.27 & 17.01 & 8.28 & 13.73 & 6.55 \\
\hline p2 & -8.37 & 4.19 & -7.91 & 3.77 & -6.48 & 3.17 \\
\hline
\end{tabular}

Note: In grey, restricted parameters.

(Table continued on next page) 
Table 6: (Continued)

\begin{tabular}{|c|c|c|c|c|c|c|}
\hline $\begin{array}{l}\text { 4. Job competition parameters } \\
\text { Lower secondary }\left(\kappa_{\tau}^{2}\right)\end{array}$ & & & & & & \\
\hline $\begin{array}{c}\text { constant } \\
\text { Upper secondary }\left(\kappa_{\tau}^{3}\right)\end{array}$ & -0.84 & 0.21 & -1.21 & 0.07 & -0.82 & \\
\hline $\begin{array}{c}\text { constant } \\
\text { Upper secondary }\left(\kappa_{\tau}^{4}\right)\end{array}$ & 0.45 & 0.17 & 0.29 & 0.11 & 0.48 & 0.17 \\
\hline $\begin{array}{c}\text { constant } \\
\text { Common time dependence }\end{array}$ & 1.81 & 0.32 & 1.81 & 0.28 & 1.88 & 0.35 \\
\hline $\mathrm{p} 1$ & 0.10 & 0.04 & 0.10 & 0.05 & 0.09 & 0.04 \\
\hline $\mathrm{p} 2$ & 0.06 & 0.03 & 0.07 & 0.03 & 0.06 & \begin{tabular}{|l|l|} 
\\
\end{tabular} \\
\hline Number of observations & 528 & & 528 & & 528 & \\
\hline Number of estimated parameters & 28 & & 24 & & 25 & \\
\hline Weighted sum of squared residuals & 501.777 & & 506.72 & & $\mathbf{5 0 5 . 8 0}$ & \\
\hline $\begin{array}{l}\text { P-value of the goodness-of-fit test } \\
\text { P-value of the restrictions test }\end{array}$ & 0.469 & & 0.293 & & 0259 & \\
\hline
\end{tabular}




\section{Appendix}

\subsection{Appendix 1: Data correction}

Since we have an inflow data set, not all duration classes are represented at the begin of the observation period. For the first three calendar time intervals, there are some durations missing. We estimate the number of unemployed in the missing duration classes by exploiting the information on the number of unemployed workers in the observed duration classes. We approximate the missing observations in the following way:

For $\tau=1$ and $k \in(2,3,4)$ :

$$
U_{a k \tau}^{i}=U_{a 1 \tau}^{i} \exp \left(-\sum_{i=1}^{k-1} \tilde{h}_{a k \tau}^{i}\right)
$$

For $\tau=2$ and $k \in(3,4)$ :

$$
U_{a k \tau}^{i}=U_{a k-1 \tau-1}^{i} \exp \left(-\tilde{h}_{a k-1 \tau}^{i}\right)
$$

For $\tau=3$ and $k=4$ :

$$
U_{a k \tau}^{i}=U_{a k-1 \tau-1}^{i} \exp \left(-\tilde{h}_{a k-1 \tau}^{i}\right)
$$

where $\tilde{h}_{a k \tau}^{i}$ is the hazard rate of an individual of type $i$ and $a$ at duration $k$ and calendar time $\tau$. This is estimated by regressing a transformation of $\hat{P}_{a k \tau}^{i}$ on duration and calendar time dummies for each combination of education level $(i)$ and age group $(a)$. This correction relies on two assumptions which only concern equation (a2): (i) The number of entrants into unemployment at $\tau \in(-2,-1,0)$ is the same as the number of entrants at $\tau=1$ and (ii) the calendar time dependence of the hazard rate at $\tau \in(-2,-1,0)$ is the same as the one at $\tau=1$. These assumptions can be justified since the state of the business cycle at the begin of our observation period was close to the one observed three quarters earlier (economic peak at the end of the eighties) ${ }^{31}$.

\subsection{Appendix 2: Identification issues}

In this appendix, we expand the expression (7) linearly around $\kappa_{\tau}^{i}=0$ in order to understand the conditions under which our parameters are identified. A Taylor series expansion of $\log \left(h_{\tau}^{i}\right)$ around $\kappa_{\tau}^{i}=0$ in equation (7) yields ${ }^{32}$ :

\footnotetext{
${ }^{31}$ In order to evaluate the sensitivity of our results to our correction, we compare them to the results obtained by making the observation period start at the $\tau=4$. Estimation results are similar.

${ }^{32}$ The individual search effectiveness $e_{a k}$, which is non-specified in this equation (7), is identified by the variation of $h^{i}$ in the duration and age dimensions.
} 


$$
\begin{aligned}
\log \left(h_{\tau}^{i}\right) \cong & (\alpha-1) \log \left(\tilde{U}_{\tau}^{i}\right)+\beta \log \left(V_{\tau}\right)+\beta \log \left(v_{i \tau}\right) \\
& +\kappa_{\tau}^{i}\left(\frac{\tilde{U}_{\tau}^{i}}{\tilde{U}_{\tau}^{i-1}}\right)^{1-\alpha}\left(\frac{v_{i-1 \tau}}{v_{i \tau}}\right)^{\beta}+\kappa_{\tau}^{i+1}(\alpha-1)\left(\frac{\tilde{U}_{\tau}^{i+1}}{\tilde{U}_{\tau}^{i}}\right)
\end{aligned}
$$

The matching elasticities, $\alpha$ and $\beta$, are identified from, respectively, the time variation of $\tilde{U}^{i}$ and $V$ in each equation. Then consider the identification of the constant term in the job competition and vacancy functions, respectively $\kappa_{0}^{i}$ in (16) and $v_{i 0}$ in (15). Identification of $\kappa_{0}^{i}$ comes from variations of the $\tilde{U}^{i}-\tilde{U}^{i-1}$ ratio in the equations of $h_{\tau}^{i}$ and $h_{\tau}^{i-1}$. If the evolution of $U^{i}$ does not exactly follows the evolution of $\tilde{U}^{i-1}$, identification of $\kappa_{0}^{i}$ is ensured. The parameter $v_{i 0}$ is then simply a constant term by schooling level, identified by the remaining variation between exit rates by schooling levels. As a consequence, we must assume that the individual search effectiveness, $e_{a k}$, does not depend on the level of education. If we allow $v_{i}$ to vary over calendar time, we cannot allow another parameter to vary simultaneously with calendar time and education. This is because only one set of parameters, $v_{i n}^{C}$ and $v_{i s}^{S}$ in (15), can capture the remaining interaction between the calendar time and the schooling level in the model. We can allow at most for a common calendar time effect in $\kappa^{i}$, i.e. $\kappa_{n}^{C}$ and $\kappa_{s}^{S}$ in (16).

\subsection{Appendix 3: Two-step estimation procedure}

In this appendix, we give the estimation procedure of the model (21):

$$
\hat{z}_{a k \tau}^{i}=\log \left(h_{a k \tau}^{i}\right)+\omega_{a k \tau}^{i}+\varepsilon_{a k \tau}^{i}, \quad i=1,2,3,4
$$

$$
\text { with the approximation error } \omega_{a k \tau}^{i}=\frac{\hat{P}_{a k \tau}^{i}-P_{a k \tau}^{i}}{\left(1-P_{a k \tau}^{i}\right) \log \left(1-P_{a k \tau}^{i}\right)}
$$

Since the number of outflows, $F_{a k \tau}^{i}$, in the empirical estimator $\hat{P}_{a k \tau}^{i}$ has a binomial distribution with a probability of 'success' $P_{a k \tau}^{i}$ conditional on the number of individuals at risk, $U_{a k \tau}^{i}$, Cockx (1997) shows that $E\left(\omega_{a k \tau}^{i}\right)=0$ and that a consistent estimate of the variance of $\omega_{a k \tau}^{i}$ is ${ }^{33}$ :

$$
\left(\hat{s}_{a k \tau}^{i}\right)^{2}=\hat{P}_{a k \tau}^{i}\left[\left(1-\hat{P}_{a k \tau}^{i}\right)\left[\log \left(1-\hat{P}_{a k \tau}^{i}\right)\right]^{2}\right]^{-1} \frac{1}{U_{a k \tau}^{i}}
$$

\footnotetext{
${ }^{33}$ The covariance is zero.
} 
The estimated variance matrix of the approximation error, say $\hat{\Omega}_{a k \tau}$, has therefore the following form:

$$
\hat{\Omega}_{a k \tau}=\left[\begin{array}{cccc}
\left(\hat{s}_{a k \tau}^{1}\right)^{2} & 0 & 0 & 0 \\
0 & \left(\hat{s}_{a k \tau}^{2}\right)^{2} & 0 & 0 \\
0 & 0 & \left(\hat{s}_{a k \tau}^{3}\right)^{2} & 0 \\
0 & 0 & 0 & \left(\hat{s}_{a k \tau}^{4}\right)^{2}
\end{array}\right]
$$

The specification errors, $\varepsilon_{a k \tau}^{i}$, have a distribution such that $E\left(\varepsilon_{a k \tau}^{i}\right)=0$ and that $E\left(\varepsilon_{a k \tau}^{i} \varepsilon_{a k \tau^{\prime}}^{j}\right)=\sigma_{i j}$ for $c^{\prime}=c$ for all $i$ and $j$, and $E\left(\varepsilon_{a k \tau}^{i} \varepsilon_{a k \tau^{\prime}}^{j}\right)=0$ for $\tau^{\prime} \neq \tau$ for all $i$ and $j$. Their variance-covariance matrix is denoted $\Sigma$. With these distributional assumptions, the specification errors can differ across education level and can be correlated. The latter assumption is needed for given the determinants of the outflow rate by schooling level are inter-related in case of job competition. The approximation errors $\omega_{a k \tau}^{i}$ are assumed to be independent of the specification errors $\varepsilon_{a k \tau}^{i}$ for all $i$ and $\tau$. The variance-covariance matrix for the errors in model (a3) has therefore the block diagonal form (the subscripts $a k \tau$ have been replaced by one subscript denoting a particular $a, k$ and $\tau$ combination):

$$
\Lambda=\left[\begin{array}{cccc}
\Omega_{1}+\Sigma & & & \\
& \Omega_{2}+\Sigma & & \\
& & \ldots & \\
& & & \Omega_{N}+\Sigma
\end{array}\right]=\Omega+(I \otimes \Sigma)
$$

where $\Sigma$ is the variance-covariance matrix of the specification errors, $\Omega$ is the block diagonal matrix $\left[\Omega_{a k \tau}\right], I$ is an identity matrix of order $N=132$ (the number of $a, k$ and $\tau$ combinations), and $\otimes$ is the Kronecker product.

The estimation procedure consists then in two-steps. In a first step we estimate the model (a3) by Ordinary Least Squares (OLS). On the basis of the OLS residuals $\left(\hat{v}_{a k \tau}^{i}\right)$ and of the estimated variance of the approximation error $\left(\hat{s}_{a k \tau}^{i}\right)^{2}$, we can calculate a consistent estimate of the covariance matrix $\Sigma$, say $\hat{\Sigma}$ :

$$
\hat{\Sigma}=S-\frac{1}{N} \sum_{s=1}^{N} \hat{\Omega}_{s} \quad \text { with } S=\left[\left\{\frac{1}{N} \sum_{s=1}^{N} \hat{v}_{s}^{i} \hat{v}_{s}^{j}\right\}\right]
$$

where the variance-covariance matrix $S$ is the unadjusted residual covariance matrix. In a second step, we estimate the variance-covariance matrix $\Lambda$ by combining $\hat{\Omega}$ and $\hat{\Sigma}$ in the form of (d1) and apply GLS to the model (a3). 